OPEN ACCESS

Edited by:

Juergen Seibel,

Julius Maximilian University

of Würzburg, Germany

Reviewed by:

Erdinc Sezgin,

Karolinska Institutet (KI), Sweden

Iwabuchi Kazuhisa

Juntendo University, Japan

*Correspondence:

Johannes M. F. G. Aerts

j.m.f.g.aerts@lic.leidenuniv.nl

Specialty section:

This article was submitted to

Membrane Physiology

and Membrane Biophysics,

a section of the journal

Frontiers in Cell and Developmental

Biology

Received: 25 July 2019

Accepted: 25 November 2019

Published: 06 December 2019

Citation:

Aerts JMFG, Artola M, van Eijk M,

Ferraz MJ and Boot RG (2019)

Glycosphingolipids and Infection.

Potential New Therapeutic Avenues.

Front. Cell Dev. Biol. 7:324

doi: 10.3389/fcell.2019.00324

\section{Glycosphingolipids and Infection. Potential New Therapeutic Avenues}

\author{
Johannes M. F. G. Aerts*, M. Artola, M. van Eijk, M. J. Ferraz and R. G. Boot \\ Leiden Institute of Chemistry, Leiden University, Leiden, Netherlands
}

Glycosphingolipids (GSLs), the main topic of this review, are a subclass of sphingolipids. With their glycans exposed to the extracellular space, glycosphingolipids are ubiquitous components of the plasma membrane of cells. GSLs are implicated in a variety of biological processes including specific infections. Several pathogens use GSLS at the surface of host cells as binding receptors. In addition, lipid-rafts in the plasma membrane of host cells may act as platform for signaling the presence of pathogens. Relatively common in man are inherited deficiencies in lysosomal glycosidases involved in the turnover of GSLs. The associated storage disorders (glycosphingolipidoses) show lysosomal accumulation of substrate(s) of the deficient enzyme. In recent years compounds have been identified that allow modulation of GSLs levels in cells. Some of these agents are well tolerated and already used to treat lysosomal glycosphingolipidoses. This review summarizes present knowledge on the role of GSLs in infection and subsequent immune response. It concludes with the thought to apply glycosphingolipid-lowering agents to prevent and/or combat infections.

Keywords: glycosphingolipid, infection, glucosylceramide, lysosome, glycosidase, glycosyltransferase

\section{INTRODUCTION TO GLYCOSPHINGOLIPIDS}

Glycosphingolipids (GSLs) were discovered by the German chemist Johannes Thudichum while investigating the composition of the human brain in his London laboratory in the late 19th century (Thudichum, 1884). Thudichum meticulously identified the structure of the encountered novel class of lipids as consisting of a unique lipid moiety with attached sugar or phosphorylcholine groups. The hydrophobic moiety of the isolated brain lipids proved to contain as backbone a hitherto unknown D-erythro-Sphingosine, named after the mythical Sphinx for its "enigmatic properties to the enquirer." The value of Thudichum's findings was initially highly debated and did not meet recognition during his lifetime. Only 25 years after his death, Otto Rosenheim confirmed the accuracy of his publications which finally opened the present vast field of GSL research (King, 1956).

\section{Features of Glycosphingolipids}

Structure of Glycosphingolipids

In vertebrates the major form of the sphingoid base of GSLs is d18:1 sphingosine, $(2 S, 3 R, 4 E)$ 2aminooctadec-4-ene-1,3-diol. $\mathrm{N}$-acylation of sphingosine results in the lipid ceramide (Cer), the primary sphingolipid. The attachment of sugars to Cer yields GSLs (Figure 1A). Ubiquitous in brain is the simple GSL galactosylceramide (GalCer), the major lipid constituent of myelin insulating axons of neuronal cells and formed as extended plasma membrane of oligodendrocytes. Following Thudichum's seminal findings, it became apparent that GSLs are not restricted to the 

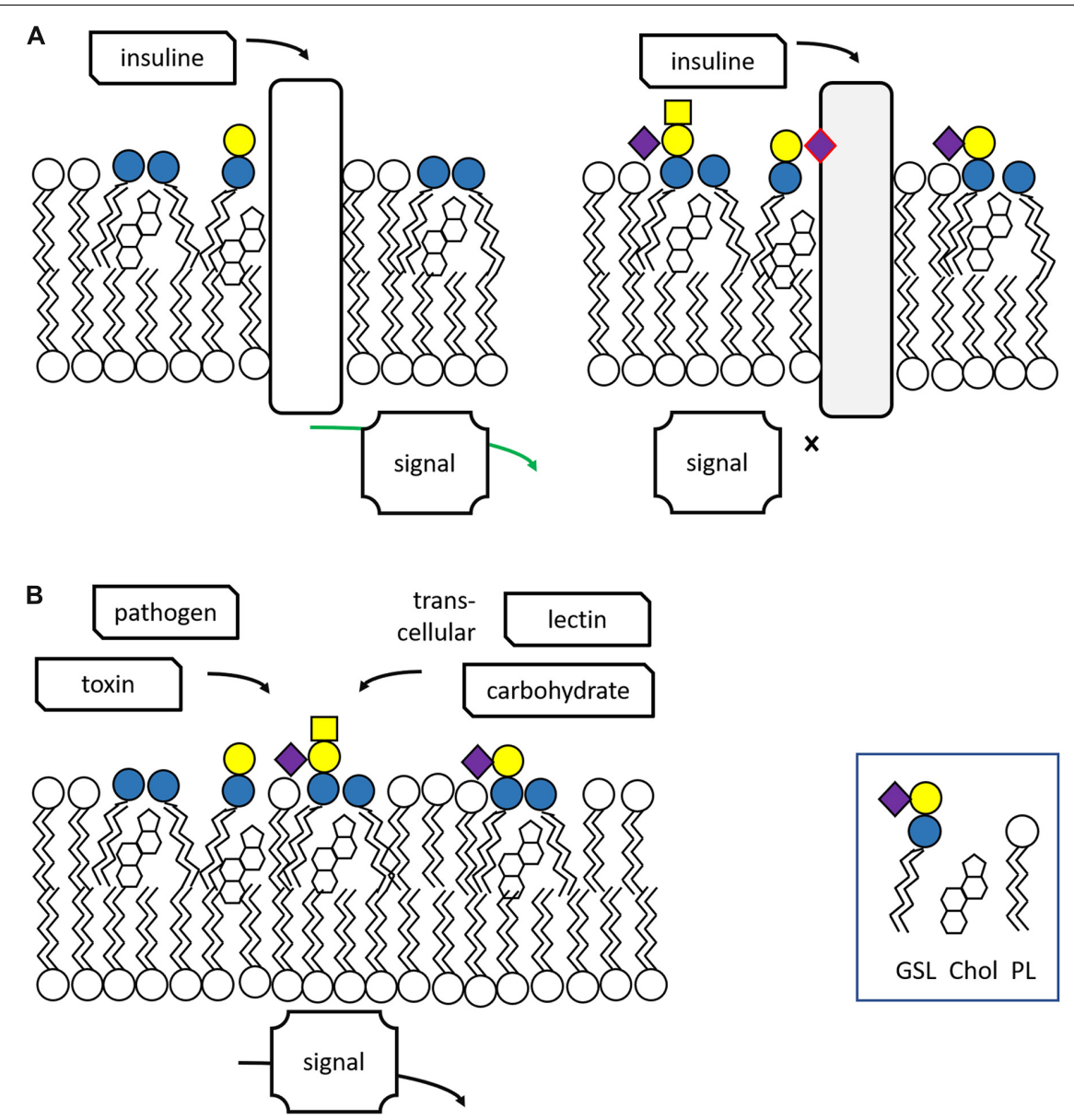

FIGURE 1 | Structure and synthesis of glycosphingolipids. (A) Synthesis of complex glycosphingolipids (GSLs) from the simple building blocks L-serine, fatty acyl-CoA, and UDP-sugars. (B) General structure of glycosphingolipid: indicated are the major globo-, isoglobo-, ganglio-, lacto-, and neolacto-series core structures.

brain but are common components of cells in various organisms. In the case of human GSLs, the first monosaccharide linked to Cer is either glucose or galactose. Additional sugars can be further attached to glucosylceramide (GlcCer) or GalCer, resulting in a plethora of lipids of which quantitatively the most abundant are the ganglio-, globo-, and neolacto-series of GSLs (Figure 1B). The structural diversity of GSLs and their nomenclature have been thoroughly reviewed (Wennekes et al., 2009; Merrill, 2011; Merrill and Sullards, 2017).

\section{Synthesis of Glycosphingolipids}

During their life in cells, GSL molecules traverse various subcellular compartments where specific modifications in their structure may occur (Wennekes et al., 2009; Gault et al., 2010; Merrill, 2011; Fabrias et al., 2012; D’Angelo et al., 2013; Tidhar and Futerman, 2013; Sandhoff and Sandhoff, 2018; Sandhoff et al., 2018). The synthesis starts at the endoplasmic reticulum (ER) where the enzyme serine palmitoyltransferase (SPT) generates keto-sphinganine from serine and palmitoylCoA (Figure 1A). This building block is next converted to sphinganine by 3-ketodihydrosphingosine reductase (KDSR).
Subsequently, a series of ceramide synthases (CerS 1-6) form dihydroceramides with amide-linked fatty acyl moieties. Distinct dihydroceramides are generated since the various CerS enzymes have different acyl-CoA length preferences (Tidhar and Futerman, 2013). From these dihydroceramides the enzyme dihydroceramide desaturase-1 (DES1) forms Cer. The primary sphingolipid Cer is subject to further metabolism and its levels are tightly controlled in this manner, a necessity for cells since Cer promotes concentration-dependently apoptotic processes, and subsequent cell death (Zelnik et al., 2019). Cer may be converted into sphingomyelin (SM; phosphocholine-ceramide) or ceramide-1-phosphate (Cer1P). It may be also degraded by neutral ceramidases to fatty acid and sphingosine (Wennekes et al., 2009). A third metabolic route involves formation of structurally diverse GSLs through distinct pathways. In tissues like kidney and brain a large portion of newly formed Cer molecules enter the ER where conversion to GalCer occurs, catalyzed by the enzyme galactosylceramide synthase (CGT) using UDP-galactose as sugar donor (Sprong et al., 1998; van Meer et al., 2003). Sulfation of GalCer molecules may take place to generate sulfatide (sulfo-GalCer). More commonly, the Cer 
transfer protein (CERT) transports newly formed Cer to the cytosolic leaflet cis-Golgi membranes (Hanada et al., 2003, 2009). Here, the enzyme glucosylceramide synthase (GCS; encoded by the UGCG gene) may transform Cer to GlcCer using UDPglucose as sugar donor (Ichikawa et al., 1996). Some of the GlcCer in the cytosolic membrane leaflet is metabolized back again to Cer by the enzyme GBA2, a cytosol-faced $\beta$-glucosidase that also shows transglucosylase activity (van Weely et al., 1993; Boot et al., 2007; Marques et al., 2016). However, most newly formed GlcCer enters the Golgi apparatus where it can be stepwise modified by glycosyltransferases (Wennekes et al., 2009; Merrill, 2011; Merrill and Sullards, 2017; Sandhoff and Sandhoff, 2018). The addition of further sugars to GlcCer yields various types of GSLs (Figure 1B). Increasing the vast diversity of GSLs is the sulfation of particular lipids. After being modified in the Golgi apparatus, GSLs end up in the outer leaflet of the plasma membrane. GSLs may partly leave cells through incorporation in HDL-lipoproteins (Van den Bergh and Tager, 1976).

Congenital human disorders of ganglioside biosynthesis are very rare. Mutations in ST3GAL5 (encoding GM3 synthase) cause severe congenital infantile seizures. Mutations in B4GALNT1 (encoding GM2/GD2 synthase) lead to hereditary spastic paraplegia accompanied by intellectual disability ( $\mathrm{Li}$ and Schnaar, 2018).

\section{Degradation}

Glycosphingolipids are internalized via endocytosis and end up in multi-vesicular bodies in endosomes. Next, their fragmentation takes place in lysosomes (Cox and Cachón-González, 2012; Platt, 2014). Through endocytosis lysosomes acquire also exogenous GSLs. These are components of phagocytosed senescent cells and debris as well as endocytosed lipoproteins. In the acid lysosomes, GSLs are fragmented by a series of glycosidases in a stepwise manner (Ferraz et al., 2014; Breiden and Sandhoff, 2019). In this process, specific glycosidases remove terminal sugar moieties from GSLs, the reverse of the biosynthetic pathway. Many of the lysosomal glycosidases fragmenting GSLs are assisted in their activity by specific accessory proteins (GM2 activator protein and saposin A-D) (Ferraz et al., 2014; Breiden and Sandhoff, 2019). Cer, the lipid product of lysosomal GSL degradation, is cleaved by the lysosomal acid ceramidase into sphingosine and fatty acid. The degradation products (sugars, fatty acids, and sphingosine) are exported to the cytosol. The exported sphingosine may be next re-used in the salvage pathway that generates again Cer molecules for the synthesis of SM or GSLs. Alternatively, sphingosine is transformed by sphingosine kinases (SK1 and SK2) to sphingosine-1phosphate (S1P). This may be subsequently degraded by S1P lyase into phosphatidylethanolamine and 2-trans-hexadecenal (Pyne et al., 2016).

\section{Functions of Glycosphingolipids Lipid Raft Signaling Platforms}

Glycosphingolipids reside primarily in the cellular plasma membrane with their sugar moieties exposed to the exterior. At the cell surface, GSLs have multiple functions. Through interactions among GSL molecules and cholesterol molecules via hydrogen bonds and van der Waal's forces semi-ordered domains spontaneously form in the plasma membrane. In these lipid rafts specific proteins involved in signaling events locate (Mukherjee and Maxfield, 2004; Lingwood and Simons, 2010; Sonnino and Prinetti, 2013; Figure 2A). It has become clear that GSLs in lipid rafts may regulate the activity of some of these signaling receptors. A particularly well studied example of the impact of gangliosides on receptor signaling concerns the epidermal growth factor receptor (EGFR). Well-established is the inhibitory effect of GM3 on the receptor's kinase domain activation, a phenomenon abolished by conversion of GM3 to lactosylceramide (LacCer) or the K642G amino acid substitution in the EGFR (Coskun et al., 2011). Thus, GM3 modulates the allosteric structural transition from inactive to signaling EGFR dimer. Another example forms the insulin receptor whose activity is influenced by local gangliosides (Kabayama et al., 2007; Langeveld and Aerts, 2009). Obese mice genetically unable to synthetize the ganglioside GM3 show better glucose tolerance and insulin sensitivity than control obese animals (Tagami et al., 2002; Yamashita et al., 2003). Pharmacological reduction of GSLs, including that of gangliosides, improves markedly insulin sensitivity and glucose homeostasis in obese rodents (Aerts et al., 2007; Zhao et al., 2009). Of note, patients with Gaucher disease (GD) (see section "Lysosomal Glycosphingolipid Storage Disorders and Therapy" for a detailed description of this inherited disorder) show elevated levels of the gangliosides GM3 in cells and tissue and in parallel reduced insulin sensitivity (Ghauharali-van der Vlugt et al., 2008; Langeveld et al., 2008).

A similar modulatory role for gangliosides has also been noted for other receptors such as the T-cell receptor amongst others (Inokuchi et al., 2018). Recently gangliosides were found to also impact on the activity of the membrane embedded protein NPC1L1, critically involved in intestinal cholesterol absorption (Nihei et al., 2018). Another intriguing finding is that the ganglioside GM1 prevents oligomerization of b-amyloid oligomers, whilst SM promotes this (Amaro et al., 2016). This finding may proof to be relevant to design strategies to ameliorate Alzheimer's disease (Amaro et al., 2016). LacCer-enriched lipid rafts have been identified in plasma and granular membranes of human neutrophils (see Nakayama et al., 2018 for a review). The first report on LacCer-raft mediated neutrophil function concerned superoxide generation (Iwabuchi and Nagaoka, 2002). It was demonstrated that the incubation of neutrophils with anti-LacCer antibody induced generation of superoxide. A key role for activation of Lyn in the process was identified (Iwabuchi and Nagaoka, 2002).

Glycosphingolipids have been found to also interact other cells, either via protein-carbohydrate or carbohydratecarbohydrate interactions (Figure 2B). The proteins involved in such interactions are three major classes of lectins: selectins binding sialylated and fucosylated glycans; siglecs binding galectins and sialylated glycans; and galectins binding glycans containing terminal galactose (Schnaar, 2004).

In land animals, GSLs fulfill a special function in the outermost skin, the stratum corneum. Here, extraordinary GlcCer molecules with very-long-chain fatty acid (C30-32) and an $\omega$-hydroxyl group esterified to another fatty acid are obligate precursors 


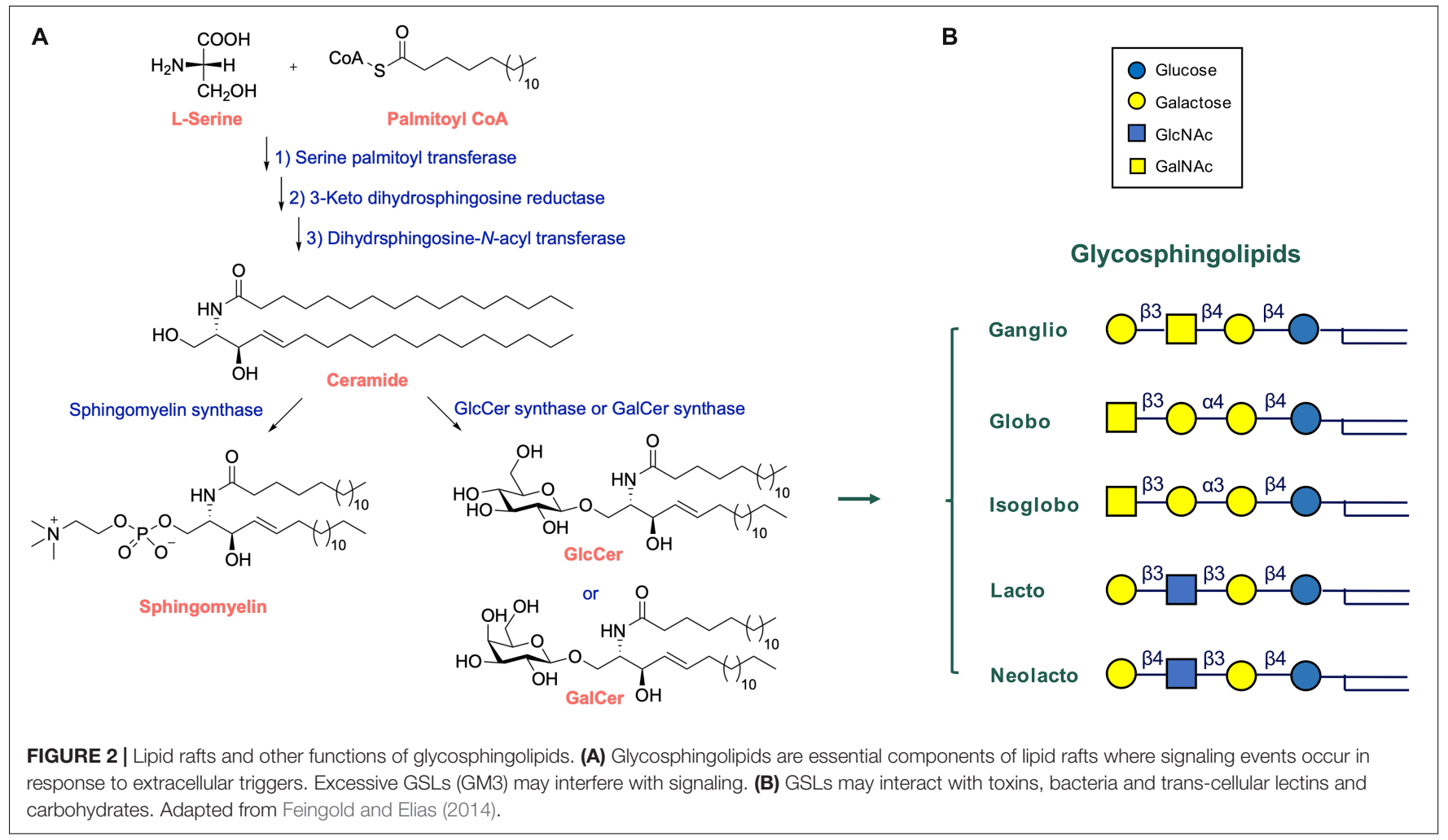

to Cer that are locally required to build the desired protective and permeability layer (Feingold and Elias, 2014; Van Smeden and Bouwstra, 2016; Wertz, 2018). Disturbance in skin GlcCer and Cer are associated with severe, even fatal, dysfunction of the skin (Van Smeden et al., 2017). The presence of specific gangliosides in neurons has multiple functions and proves to be essential for optimal interplay with the insulating myelin (Lopez and Báez, 2018). In particular, lack of specific gangliosides in axons of neurons leads to disturbed interaction with myelinassociated glycoprotein (MAG) in the innermost membrane of myelin. This impairment is thought to underly the spastic paraplegia during neuronal deficiency of specific gangliosides (Schnaar and Lopez, 2009).

Exposed glycans of GSLs on epithelial cells contribute to the protective properties of the glycocalyx of internal body linings. A similar type of protective function of GSLs is envisioned for lysosomes inside cells. Beside the outer leaflet plasma membrane, the inner leaflet of the lysosomal membrane is rich in GSLs. This membrane also contains integral membrane proteins that are decorated with $\mathrm{N}$-linked glycans. By the combined presence of GSLs and membrane glycoproteins the lysosomal membrane is thought to be protected by a sugar barrier against selfdegradation by the proteases and lipases present in the lumen of the compartment (Schwake et al., 2013).

Specific GSLs at the surface of cells also undergo specific interactions with the outside world. For example, some GSLs contain the glycan-based ABO antigens, crucial in self-recognition and of importance in transfusion medicine (Kościelak, 2012). E-selectin mediated binding of tissue invading leukocytes to endothelial cells is known to be dependent on specific GSLs (Nimrichter et al., 2008).

\section{Glycosphingolipids and Infection} Interaction With Pathogens and Toxins

Many viruses, bacteria, and bacterial toxins bind to carbohydrates of GSLs on host cell surfaces (Figure 3). Recommended reviews of the topic are Nakayama et al. (2018) and Hanada (2005).

\section{Viruses}

Some viruses are known to exploit GSLs in their life cycle in hosts (Lingwood, 1996). One well studied example is the human immunodeficiency virus (HIV) (Lingwood and Branch, 2011). HIV virions enter their host cells by the binding of the viral envelope gp120 to the primary receptor CD4, an essential interaction for viral fusion and entry. $G$ protein-coupled $\alpha$ - and $\beta$-chemokine receptors are required as "co-receptors" together with CD4 for HIV-1 infection. GSLs display a complex interaction with HIV gp120, with reports suggesting functions as alternate entry receptors, facilitators for HIV infection, as well as natural resistance factors for HIV infection. Several GSLs (Gb3, GM3, GalCer, sulfatide) appear to bind the HIV adhesin gp120 (Lund et al., 2009; Lingwood and Branch, 2011). Upon binding, GSLs such as GalCer and GM3 facilitate subsequent interaction of the virus with its chemokine co-receptor on the cell surface (Lingwood and Branch, 2011). In contrast, Gb3 may successfully compete for co-receptor binding, and prevent fusion and viral entry (Lund et al., 2009; Lingwood and Branch, 2011). Polyomavirus invades human erythrocytes via the gangliosides 


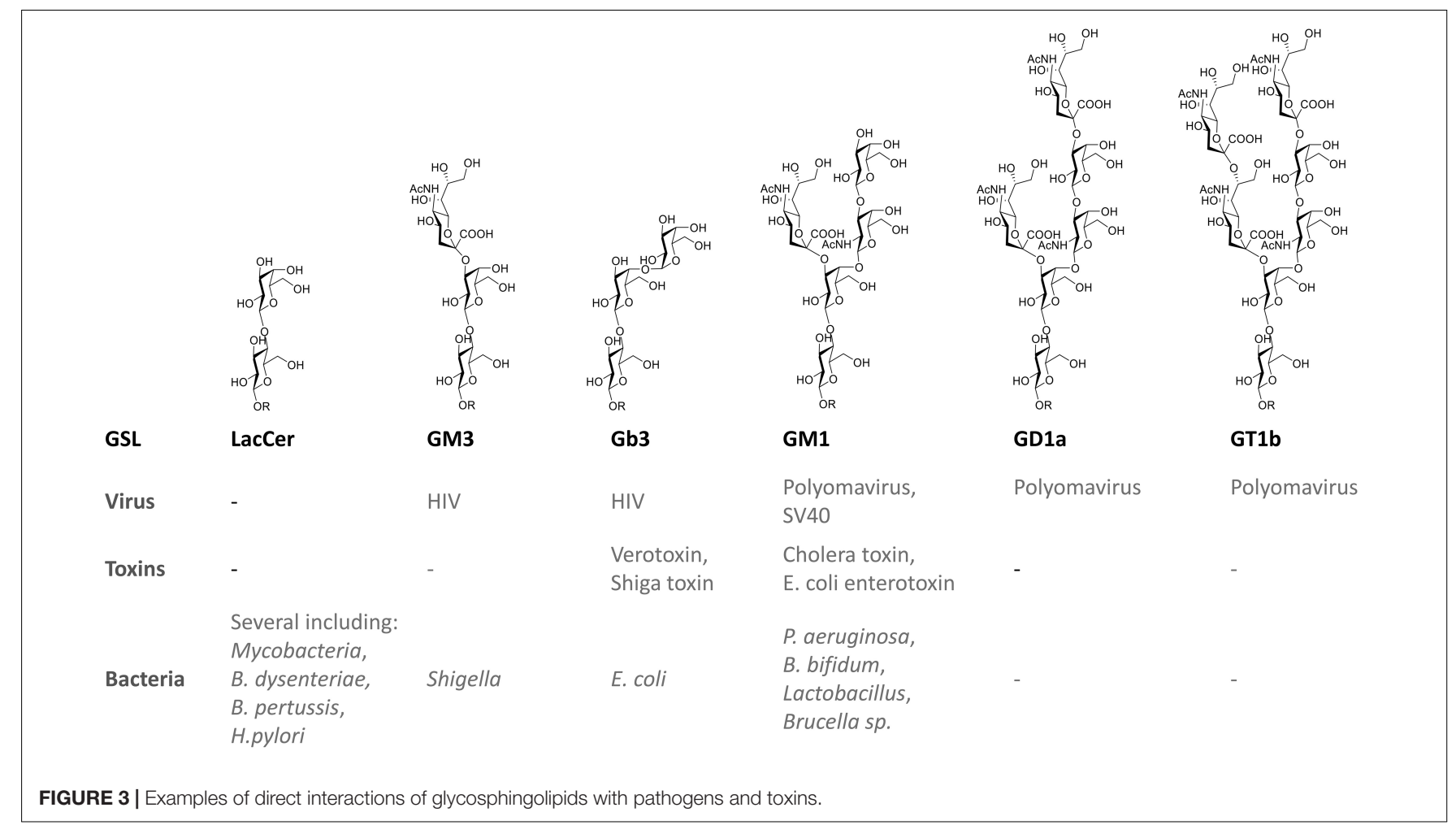

GD1a and GT1b (Schwake et al., 2013). GM1 has also been shown to act as receptors for simian virus 40 (SV40) and polyoma virus (Tsai et al., 2003).

\section{Toxins}

Protein toxins show an $\mathrm{AB}$ structure, with a catalytic A domain and a $\mathrm{B}$ domain encoding host receptor recognition (Zuverink and Barbieri, 2018). Gb3, (a.k.a. CD77 or P(k) blood group antigen) is known to bind to Shiga toxin and the closely related Escherichia coli (E. coli) derived verotoxin B subunit (van Heyningen, 1974). The globoside thus is mediating verotoxin induced hemolytic uremic syndrome (HUS) (Lingwood, 1996). The ganglioside GM1 serves as the primary receptor for cholera toxin and the highly homologous $E$. coli heat-labile enterotoxin (Hirst et al., 2002). Clostridium tetani neurotoxin and Clostridium botulinum neurotoxin type $\mathrm{A}$ and $\mathrm{B}$ use several gangliosides as receptors (Kitamura et al., 1999). The ganglioside GM2 acts as a receptor for delta-toxin of Clostridium perfringens (Jolivet-Reynaud et al., 1989). Cholera toxin B subunit (CTB) binds to GM1 enriched in lipid rafts (Cuatrecasas, 1973a,b). GM1 on epithelial cells also binds E. coli enterotoxin (Hyun and Kimmich, 1984; Masserini et al., 1992; Kuziemko et al., 1996). The gangliosides present in human milk are thought to compete the binding of Vibrio cholerae and E. coli enterotoxins in the intestine and thus offer protection (Otnaess et al., 1983; Newburg and Chaturvedi, 1992).

\section{Bacteria}

The ganglioside asialo-GM1 (GA1) at the surface of epithelial cells binds Bifidobacterium bifidum, Pseudomonas aeruginosa, and Lactobacillus (de Bentzmann et al., 1996; Mukai et al., 2004).
The ganglioside GM1 has been implicated in infections with Brucella species (Naroeni and Porte, 2002; Martín-Martín et al., 2010). Fimbriated E. coli bind to the globosides Gb3 and Gb4 (Leffler and Svanborg-Edén, 1981). Virulent strains of Bordetella pertussis, a human respiratory pathogen, bind with high affinity to sulfatide (Brennan et al., 1991). Mycoplasma pneumoniae appears to exploit GSLs containing terminal $\mathrm{Gal}\left(3 \mathrm{SO}_{4}\right) \beta 1$ residues (Krivan et al., 1989).

The neutral GSL LacCer at the surface of intestinal epithelial cells binds various microorganisms. These include Candida albicans, B. pertussis, Mycobacterium tuberculosis, E. coli, Bacillus dysenteriae, and Propionibacterium freudenreichii (Nakayama et al., 2018). Possibly milk-derived LacCer protects the host from invading pathogens. Interactions between the sugar moieties of gangliosides and the polysaccharide moieties of Shigella lipopolysaccharide were found to facilitate binding of bacteria to human CD4+ T cells (Belotserkovsky et al., 2018). There are indications that the adhesion of Helicobacter pylori, causing chronic active gastritis, peptic ulcer disease and gastric adenocarcinoma, depends on gangliosides in the human stomach. The gangliosides Neu5Aca3-neolactohexaosylceramide and Neu5Aca3-neolactooctaosylceramide mediate attachment of H. pylori SabA (sialic acid binding adhesin) there (Mahdavi et al., 2002; Benktander et al., 2018).

\section{Immune System}

The role of GSLs in immune cell functions receives increasing interest and has been recently reviewed (Zuidscherwoude et al., 2014; Zhang et al., 2019). Besides acting as entry point of pathogens and toxins, GSLs also impact on the response of 
the immune system to pathogens. As such, GSLs themselves can also transduce signals as revealed by the effect of their crosslinking by multivalent binders such as bacterial toxins, or alternatively IgM antibodies (Spiegel, 1989; Klokk et al., 2016). Influx of calcium ions upon cell surface crosslinking of GM1 seems to be largely mediated by L-type calcium channels (Carlson et al., 1994). As another example, in human neutrophils LacCer forms specific lipid rafts in the plasma membrane as well as granular membranes. These rafts have been shown to interact with $\beta$-glucan of $C$. albicans and lipoarabinomannan (LAM) of Mycobacteria (Sato et al., 2006; Nakayama et al., 2016). Such binding triggers signaling cascades involving Src family kinases. The responses to this are chemotaxis, phagocytosis, and phagolysosome formation. In neutrophils, M. tuberculosis smartly targets the LacCer-enriched lipid rafts in phagosomes to inhibit the maturation of phagosome to lytic phagolysosomes (Nakayama et al., 2018).

Other direct and indirect interactions of GSLs with immune cells affecting their activity have more recently come to light. For example, the C-type lectin receptor Mincle (macrophage inducible C-type lectin), contributes to innate immune responses by recognition of lipids stemming from foreign pathogens like glucose and trehalose mycolates and glycosyl diacylglycerols, but also lipids from damaged cells (Williams, 2017). Among the reported Mincle-interacting self antigens are sterols but also GlcCer (Nagata et al., 2017).

In the case of dendritic cells, glycolipid antigens are presented by $\mathrm{MHC}$ class I molecule (CD1d) of dendritic cells via T-cell receptor recognition to activate natural killer $\mathrm{T}$ (NKT) cells which control innate and adaptive immune responses (Kumar et al., 2017). The marine sponge GSL $\alpha$-GalCer is identified as potent lipid antigen activating invariant NTK (iNKT) cells. These cells are also activated by the endogenous iGb3Cer (Gal $\alpha 1-3 \mathrm{Gal} \beta 1$ $4 \mathrm{Glc} \beta \mathrm{Cer}$ ) (Pei et al., 2012). More recently, excessive GlcCer has also been proposed to act as an iNKT cell activator (Nair et al., 2015). Of note, GlcCer synthase deficiency in mouse cells was already earlier reported to impair CD1d-dependent activation of iNKT cells, suggesting that GlcCer or its metabolites might be endogenous ligands for CD1d-restricted iNKT cells (Stanic et al., 2003).

In addition to modulating innate immunity, GSLs also appear to play critical roles in adaptive immunity. For example, gangliosides influence $\mathrm{T}$ cell receptors (TCRs) on CD-4 positive (CD4+) and CD-8 positive $(\mathrm{CD} 8+) \mathrm{T}$ cells, respectively (Nagafuku et al., 2012). Here it is thought that the precise ganglioside composition of lipid rafts in specific $\mathrm{T}$ cell populations is a prerequisite for their associated specific effector functions. This regulatory aspect of gangliosides in $\mathrm{T}$ cell biology seems highly relevant for allergic and autoimmune diseases and has been topic of excellent reviews (Inokuchi et al., 2018; Nakayama et al., 2018).

In some specific autoimmune neuropathies affecting the nervous system the autoimmune attack is due to antibodies reactive with gangliosides. Anti-ganglioside antibodies occur for example with Guillain-Barré syndrome. These antibodies may be induced by infections with pathogens containing glycan components that are structurally similar to gangliosides.
The most important example of this is Campylobacter jejuni whose surface lipo-oligosaccharide mimics GD1a, GT1a, GM1, and other gangliosides (Goodfellow and Willison, 2018). Binding of autoantibodies on gangliosides activates locally complement and recruits macrophages, causing local impairment of nerve conduction in these patients.

\section{Sphingomyelin and Infection}

Sphingomyelin is the most abundant cellular sphingolipid. Like GSLs, SM is also implicated in infections and the immune system's response to these (Wu et al., 2018; Li et al., 2019). For example, mice with deficiency of acid sphingomyelinase (ASMase; Sphingomyelin phosphodiesterase 1), the enzyme hydrolyzing SM to Cer and phosphorylcholine, are strongly susceptible to Citrobacter rodentium-driven colitis (Meiners et al., 2019). Mice overexpressing ASMase in $\mathrm{T}$ cells show increased $\mathrm{T}$ cell activation and reduced parasitemia in upon infection with Plasmodium yoelii (Hose et al., 2019). Two forms of ASMase are encoded by the SMPD1 gene: a lysosomal form (L-ASMase) and a secretory form (S-ASMase). Although ASMase has an acid $\mathrm{pH}$ optimum for activity, the same enzyme, when secreted, also catalyzes the hydrolysis of SM in the circulation and on the plasma membrane (Smith and Schuchman, 2008; Schuchman, 2010). ASMase deficiency results in the accumulation of SM in lysosomes and causes the neuropathic (type A) and non-neuropathic (type B) variants of NiemannPick disease (Schuchman, 2010). Generation of Cer molecules on the cell surface by ASMase leads to formation of Cerenriched domains, distinct from traditional lipid rafts, that act as platforms governing signaling events (Li et al., 2019). Cerenriched platforms occur in cells upon diverse receptor or non-receptor stimuli, including CD95, FcyRII, CD40, plateletactivating factor receptor (PAF), viral infection, $P$. aeruginosa, Neisseria gonorrhoeae, Staphylococcus aureus, cisplatin, $\mathrm{Cu}^{2+}$, irradiation and UV-light (Li et al., 2019). The interaction of Cer-enriched platforms with CD95, the death receptor Fas, is the best understood. CD95 induces an increased ASMase activity on the cell surface, thus generating Cer-enriched platforms amplifying CD95 signaling (Gulbins and Grassmé, 2002; Grassmé et al., 2007).

The ASMase/Cer system has been implicated in infections with pathogens. $P$. aeruginosa is a gram-negative bacterium commonly affecting immune-compromised patients and patients with chronic wounds, sepsis, or chronic emphysema. Patients with cystic fibrosis (CF) have a particular risk for chronic $P$. aeruginosa infections. The infection of mammalian cells with different strains of $P$. aeruginosa induces the rapid activation of ASMase and translocation to the plasma membrane ( $\mathrm{Li}$ et al., 2019). Generated Cer-rich rafts by ASMase mediates the internalization of $P$. aeruginosa, which is prevented by inhibitors of the ASMase or by ASMase-deficiency. Amitriptyline, a tricyclic antidepressant (TCA), is a functional ASMase inhibitor. Administration of amitriptyline to CF mice normalizes pulmonary Cer levels and abolishes pathological outcome, including susceptibility to infection (Becker et al., 2010). Amitriptyline might therefore offer in the future a novel medicine to treat CF patients. 
ASMase appears critical in the regulation of host interactions with other bacteria as well, including S. aureus, Mycobacteria, Listeria monocytogenes and Neisseria species. S. aureus, is a commensal opportunistic bacterium that colonizes approximately $30 \%$ of human populations. It may cause lifethreatening endocarditis, diseases, sepsis, toxic shock syndrome, and pneumonia (Li et al., 2019). S. aureus is the primary cause of sepsis and lethal lung edema. Mice treated with the ASMase inhibitor amitriptyline show reduced lung edema upon $S$. aureus exposure. The effect on sepsis of various ASMase inhibitors (imipramine, desipramine, and amitriptyline), is presently studied in animal models (Chung et al., 2018; Xia et al., 2019).

\section{Lysosomal Glycosphingolipid Storage Disorders and Therapy}

Inherited defects in lysosomal enzymes fragmenting GSLs lead to accumulation of the accompanying substrate in lysosomes. Several inherited lysosomal glycosphingolipid storage disorders (glycosphingolipidoses) occur in humans, see Figure 4 (Cox and Cachón-González, 2012; Ferraz et al., 2014; Platt, 2014; Breiden and Sandhoff, 2019).

\section{Gaucher Disease}

A prototype glycosphingolipidosis is GD, named after Ernest Gaucher who published the first case report (Beutler and Grabowski, 2001). GD is a recessively inherited disorder stemming from mutations in the GBA gene. This codes for an acid $\beta$-glucosidase, better known as glucocerebrosidase (GCase; EC. 3.2.1.45) (Brady et al., 1966; Beutler and Grabowski, 2001). The 497 amino acid glycoprotein cleaves GlcCer to Cer, the penultimate step in lysosomal breakdown of most GSLs. Prominent GlcCer accumulation characteristically occurs in tissue macrophages (Gaucher cells) of GD patients. The clinical presentation of GCase deficiency is very heterogeneous, from severe neonatal complications to a virtually asymptomatic course. Non-neuronopathic (type 1), acute neuronopathic (type 2), and sub-acute neuronopathic (type 3) GD phenotypes are discerned. A complete deficiency of GCase causes fatal skin pathology causing abnormal permeability properties (Beutler and Grabowski, 2001). It has recently been recognized that individuals with a mutant GBA allele are at increased risk, about 20-fold, to develop Parkinson disease (Siebert et al., 2014). Although some mutations in the $G B A$ gene are associated with a benign GD disease course, e.g., the amino acid substitution N370S, the GBA genotype proves to poorly predict actual disease presentation in GD patients. Considerable variability in symptoms and general disease severity is documented for several GBA genotypes, even among monozygotic twins (Ferraz et al., 2014). The molecular basis for the interindividual variability in outcome of GCase deficiency among GD patients is not identified yet.

\section{Putative advantage of GD heterozygotes}

Another intriguing aspect of GD forms the high incidence among Ashkenazim with a disease allele frequency at approximately $0.03-0.04$, around 10 -fold higher than in non-Jewish populations
(Beutler and Grabowski, 2001). The elevated incidence of GD in Ashkenazi Jews is due to four common mutations (Koprivica et al., 2000). The elevated incidence of GD (and other lysosomal storage disorders in glycosphingolipid metabolism such Niemann-Pick disease type B and Tay-Sachs disease) in Ashkenazi populations has led to a great deal of speculation about its cause, ranging from founder effects to a heterozygote advantage. A founder effect as cause seems very unlikely given the small size of the founding Ashkenazi populations in Eastern Europe (Diamond, 1994). The origin of the common N370S mutation in Ashkenazi Jews is thought, based on haplotype data, to have arisen too recently, a mere thousand years ago, to explain the current allele frequency as the result of genetic drift alone (Boas, 2000; Colombo, 2000). The increased allele frequencies of four GBA mutations in Ashkenazi Gaucher patients makes this additionally statistically improbable (Diamond, 1994; Diaz et al., 2000). It therefore has been speculated that GD carriers may be less vulnerable to infectious diseases that cause many victims in city-dwelling populations such as bubonic plaque or tuberculosis. Macrophages are key players in GD and Niemann-Pick disease type B and these cells host $M$. tuberculosis. Evidence for the appealing carrier advantage hypothesis is still missing. Of note, in a zebrafish model of tuberculosis (M. marianum) deficiency of several lysosomal hydrolases increases vulnerability for the infection, however, interestingly not that of GCase (Berg et al., 2016; Meijer and Aerts, 2016).

\section{Gaucher cells and their secreted markers}

Characteristic lipid-laden macrophages accumulate in the spleen, liver, bone marrow, lymph nodes, and lung of GD patients. These Gaucher cells are metabolically active, alternatively activated, macrophages (Boven et al., 2004). GD patients develop lowgrade inflammation and coagulation, and show activation of the complement cascade (Hollak et al., 1997; Vissers et al., 2007). Gaucher cells over-express and secrete specific proteins into the circulation of which some are presently employed as biomarkers of body burden of storage macrophages (Ferraz et al., 2014). Examples are chitotriosidase, the human chitinase (Hollak et al., 1994; Bussink et al., 2006), the chemokine CCL18/PARC (Boot et al., 2004) and a soluble fragment of gpNMB (Kramer et al., 2016). Interestingly, increased levels of plasma chitotriosidase also occur with some infectious disease involving macrophages such as Leishmaniasis, tuberculosis, malaria, and leprosy (Hollak et al., 1994; Aerts et al., 2008; Iyer et al., 2009; Di Rosa et al., 2016).

\section{Metabolic Adaptations to GCase Deficiency for Better or Worse}

Striking metabolic adaptations occur during GCase deficiency (Ferraz et al., 2014). Firstly, increased anabolism of GlcCer to gangliosides takes place, contributing to insulin resistance (Langeveld and Aerts, 2009). Another adaptation involves the cytosol-faced retaining $\beta$-glucosidase GBA2. Increased activity of this enzyme during GCase deficiency leads to increased formation of pro-apoptotic Cer from GlcCer. Reducing GBA2 activity, genetically or by means of small compound 


\section{A}

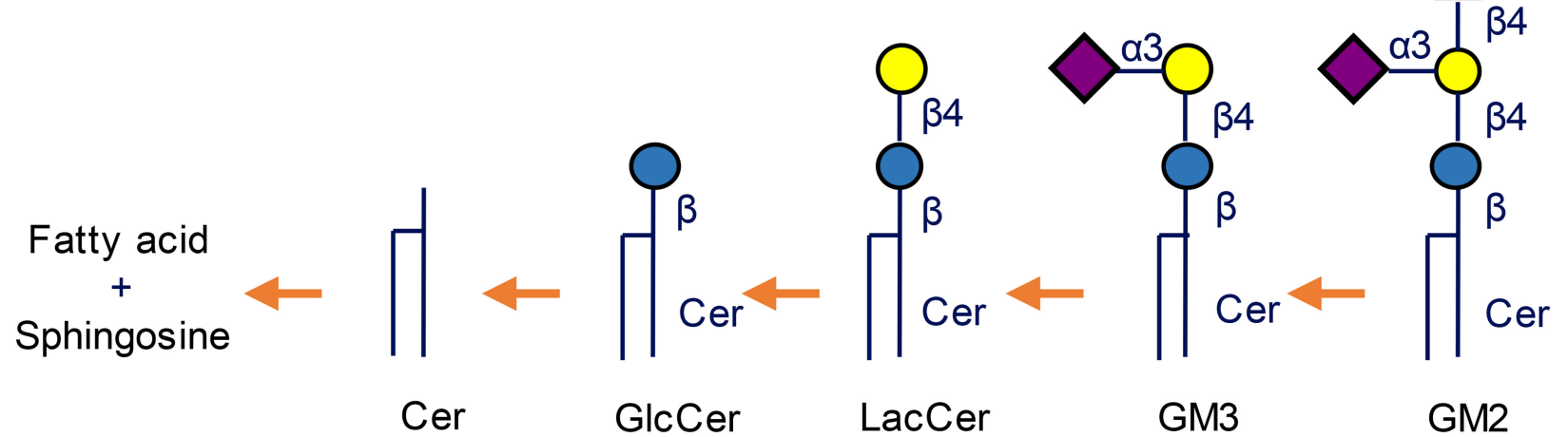

B

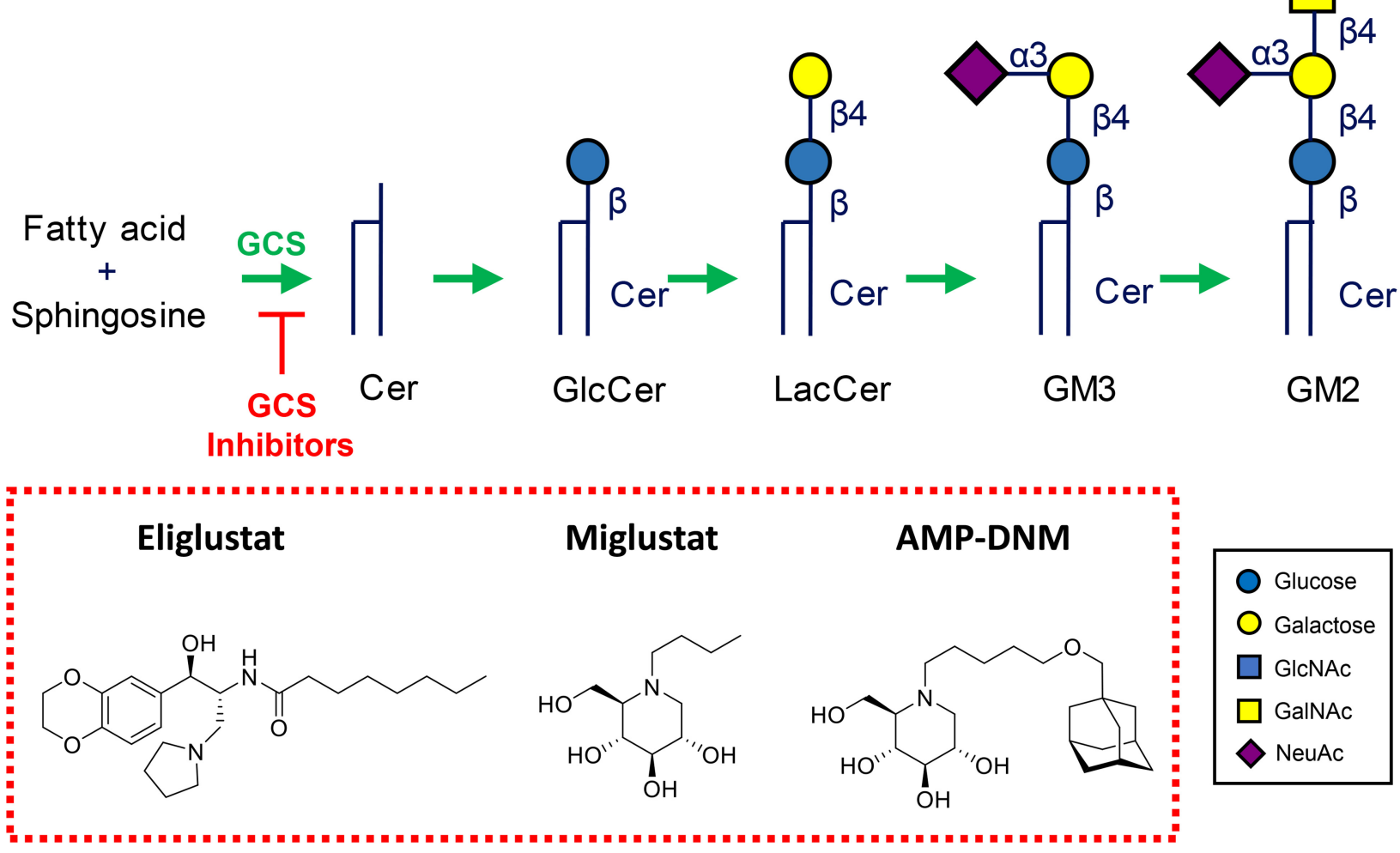

FIGURE 4 | Metabolism of glycosphingolipids. (A) Lysosomal degradation by glycosidases assisted by activator proteins. Indicated are common lysosomal storage disorders stemming from inherited defects in lysosomal hydrolases. (B) Therapeutic reduction of glycosphingolipids by inhibition of glucosylceramide synthase (GCS). Shown are two clinically registered GCS inhibitors (Miglustat, N-butyl-deoxynojirimycin) and Eliglustat (N-[(1R,2R)-1-(2,3-Dihydro-1,4-benzodioxin-6-yl)

-1-hydroxy-3-(1-pyrrolidinyl)-2-propanyl]octanamide), and AMP-DNM (N-(5-adamantane-1-yl-methoxy-pentyl)-deoxynojirimycin) commonly employed in research.

inhibitors like the iminosugar AMP-DNM, has remarkable beneficial effects in Niemann Pick type C (NPC) mice with a defect in the lysosomal protein NPC1 mediating efflux of cholesterol from lysosomes and secondary GCase deficiency (Nietupski et al., 2012; Marques et al., 2015). AMP-DNM treatment also exerts a neuro-protective effect in mice with Sandhoff disease, another glycosphingolipid storage disorder (Ashe et al., 2011). Of note, GBA2 can act as transglycosylase, transferring the glucose from GlcCer to cholesterol and forming glucosyl- $\beta$-cholesterol (GlcChol) in the process (Marques et al.,
2016). Another adaptation during GCase is the conversion of accumulating GlcCer in lysosomes by acid ceramidase to its sphingoid base, glucosylsphingosine (GlcSph) (Ferraz et al., 2016). GlcSph reaches the circulation and plasma GlcSph is on average 200 -fold elevated in symptomatic type 1 GD patients (Dekker et al., 2011). Measurement of elevated plasma GlcSph has come into use for laboratory confirmation of GD diagnosis (Mirzaian et al., 2015). Albeit clinically distinct diseases, the glycosphingolipidoses show as uniform response to lysosomal GSL accumulation, that is the 
conversion of storage lipid to its corresponding sphingoid base. In Fabry disease ( $\alpha$-galactosidase deficiency), Krabbe disease (galactocerebrosidase deficiency), GM2 gangliosidosis ( $\beta$-hexosaminidase deficiency), and Niemann Pick diseases types $\mathrm{A}$ and $\mathrm{B}$ (acid sphingomyelinase deficiency) the corresponding sphingoid bases of the accumulating substrates (lysoGb3, galactosylsphingosine, lysoGM2, and lysoSM, respectively) are formed and their plasma levels are markedly increased, offering diagnostic possibilities (Ferraz et al., 2014; Mirzaian et al., 2017; Marshall et al., 2019).

\section{Pathophysiology}

There is compelling evidence for a prominent role of Gaucher cells in GD pathology. Excessive GlcSph stemming from these storage cells is likely pathogenic. It is thought to contribute to the common osteopenia (reduced bone mineral density) in GD patients by impairing osteoblasts (Mistry et al., 2014), to promote $\alpha$-synuclein aggregation, a hallmark of Parkinson disease (Taguchi et al., 2017), and to underly as auto-antigen in the common gammopathies in GD patients that can evolve into multiple myeloma, a relatively common leukemia in GD patients (Nair et al., 2016). Antigenicity of GlcCer and GlcSph has been postulated to lead to complement cascade activation promoting local tissue inflammation and destruction (Pandey et al., 2017). The diminished cerebral microvascular density in a neuronopathic GD mouse has been attributed to GlcSph based on the observed ability of the sphingoid base to interfere with endothelial cytokinesis in vitro (Smith et al., 2018). At present the impact of excessive glucosylated metabolites, like GlcChol, generated by GBA2 activity during GCase deficiency is unknown.

\section{Therapies}

A very successful therapeutic intervention of type $1 \mathrm{GD}$ is enzyme replacement therapy (ERT), an approach in which patient's macrophages are supplemented with lacking enzyme by repeated intravenous infusion of therapeutic recombinant GCase (Brady, 2003). To ensure the desired targeting to macrophages, the therapeutic GCase has N-linked glycans with terminal mannose groups to favor uptake by macrophages via mannose-binding lectins like the mannose receptor at the surface of these cells. Two-weekly ERT of type 1 GD patients spectacularly reverses visceral symptoms like hepatosplenomegaly and corrects hematological abnormalities. Unfortunately, ERT does not prevent neurological symptoms due to inability of the enzyme to pass the blood brain barrier. Substrate reduction therapy (SRT) is an alternative registered treatment of type $1 \mathrm{GD}$. It aims to balance the synthesis of GlcCer with the diminished capacity of GD patients to degrade it (Platt et al., 2001; Aerts et al., 2006). In SRT orally available inhibitors of GCS are employed. Two drugs [Miglustat, $N$-butyl-deoxynojirimycin (NB-DNJ) and Eliglustat $(N-[(1 R, 2 R)-1-(2,3-D i h y d r o-1,4-$ benzodioxin-6yl)-1-hydroxy-3-(1-pyrrolidinyl)-2-propanyl] octanamide)] are presently approved for treatment of type 1 GD patients (Figure 4B). Treatment with the more potent and specific Eliglustat is found to result in visceral improvements in patients on a par with ERT (Mistry et al., 2018). Unfortunately, Eliglustat fails to penetrate the brain effectively and can neither be applied to treat neuropathic GD. The design of suitable brainpermeable inhibitors of GCS is investigated and pursued by industry and academic researchers (Shayman and Larsen, 2014). Venglustat (ibiglustat) is developed by Sanofi Genzyme for the treatment of Fabry disease, neuronopathic GD and Parkinson disease. A phase 2 clinical trial (NCT02228460) of Venglustat has recently been conducted to assess short-term safety and effects of the treatment in adult men with Fabry disease. Miglustat is a relatively poor inhibitor of GCs ( IC $_{50}$ in the micromolar range) and inhibits off-target intestinal glycosidases and in particular non-lysosomal GBA2 ( $\mathrm{IC}_{50}$ value in the nanomolar range). Albeit being brain permeable, it is presently not registered as drug to treat neuronopathic GD. Comparable, but superior, iminosugar inhibitors of GCS to Miglustat, like AMP-DNM [N-(5-adamantane-1-yl-methoxypentyl)-deoxynojirimycin] and its idose-configured analog, were developed some decades ago (Wennekes et al., 2010). These are orally available high nanomolar GCS inhibitors that have impact on GSL metabolism in brain of mice and were found to ameliorate the disease course in mice with NPC disease and Sandhoff disease (Nietupski et al., 2012; Marshall et al., 2019; Figure 4B). Through medicinal chemistry more potent and specific GCS inhibitors have been designed using idoAMP-DNM as scaffold (Ghisaidoobe et al., 2014). It should be noted that reduction of GlcCer formation by GCS results in the reduction of GlcCer and the metabolically upstream GSLs such as globosides and gangliosides. It therefore has the potential to ameliorate lysosomal storage disorders in which such compounds accumulate, such as GD, Fabry disease, GM2 gangliosidosis, Tay-Sachs disease, Sandhoff disease, GM1 gangliosidosis, and NPC disease.

\section{Pharmacological Modulation of GSLs: New Avenue for Infection Control? Therapeutic GCS Inhibitors}

Given the demonstrated importance of GSLs in infection and control thereof by the immune system (see section "Glycosphingolipids and Infection") and given the recent application of well tolerated inhibitors of GSL biosynthesis in GD patients (see section "Lysosomal Glycosphingolipid Storage Disorders and Therapy"), it is here proposed to consider use of such compounds to control and/or prevent specific infections. We argue the hypothetical case that glycosphingolipid lowering is feasible and tolerated and might be considered as new therapeutic avenue for specific infectious diseases.

\section{Supportive Findings}

Experimental support for the use of GSL-lowering agent to combat infection can be found in literature. For example, P-fimbriated E. coli are pathogenic in uncomplicated pyelonephritis. The $\mathrm{P}$ fimbriae of the bacterium bind the globosides such as Gb3 and Gb4 (Källenius et al., 1980; Leffler and Svanborg-Edén, 1981). When mice were fed with a high dose of the GSL biosynthesis inhibitor NB-DNJ, they showed a 
decrease in levels of GSLs and less susceptibility for urinary tract infection by P-fimbriated E. coli (Svensson et al., 2003).

Along the same line is the outcome of elegant studies by Inokuchi et al. $(2015,2018)$. Studies with genetically modified mice lacking specific gangliosides (GM3S-null mice expressing o-series gangliosides, but not a- or b-series gangliosides and GM2/GD2S-null mice expressing GM3 and GD3, but no other gangliosides) rendered new insights regarding the importance of the presence of specific gangliosides during allergic and autoimmune diseases. It appears that reduction of specific gangliosides might offer treatment for specific disorders of the immune system (Inokuchi et al., 2015). One example in this direction is allergic asthma, a type 1 hypersensitivity reaction, in which CD4+ $\mathrm{T}$ cells mediate Th2 cytokine (IL-4 and IL-13) production, stimulating $\mathrm{B}$ cells to produce $\mathrm{IgE}$ antibodies. GM3S-null mice show striking reduction of allergic airway responses normally induced by ovalbumin (OVA) inhalation (Nagafuku et al., 2012).

Noteworthy are also the beneficial findings made with GSL lowering agents for systemic lupus erythematosus (SLE). This autoimmune disease manifests with chronic inflammation and leads to damage of tissue (Tsokos, 2011; Kidani and Bensinger, 2014). In SLE there is a prominent $\mathrm{T}$ cell dysfunction: $\mathrm{CD} 4+\mathrm{T}$ cells from patients have lipid rafts with an altered GSL composition. Elevated GSLs (LacCer, Gb3, and GM1) in SLE patients are linked to increased expression of LXRb. The inhibition of GSL biosynthesis with NB-DNJ has been reported to correct CD4+ $\mathrm{T}$ cell signaling. In addition, it decreased anti-dsDNA antibody production by autologous B cells in SLE patients (McDonald et al., 2014).

Pharmacological reduction of GSLs is reported to exert beneficial anti-inflammatory effects. GSL-lowering by oral AMPDNM treatment of mice with trinitrobenzene sulphonic acid (TNBS)- and oxazolone-induced colitis reduced disease severity and edema and suppressed inflammation (Shen et al., 2004). Prominent anti-inflammatory effects of AMP-DNM treatment were also noted for the liver and adipose tissue of obese rodents (Bijl et al., 2009; van Eijk et al., 2009; Lombardo et al., 2012). Non-Alcoholic Fatty Liver Disease (NAFLD) develops during the metabolic syndrome. NALFD involves liver abnormalities ranging from steatosis (fat accumulation) to non-alcoholic steatohepatitis (NASH) including fibrosis and inflammation. Treatment of obese mice with AMP-DNM not only corrects glucose homeostasis and restores insulin signaling in the liver but also reduces inflammation in the tissue (Bijl et al., 2009). A subsequent study revealed that a treatment with the GSL-lowering AMP-DNM is able to significantly correct pre-existing NASH (Lombardo et al., 2012). During obesity, inflammation of adipose tissue is thought to significantly contribute to pathophysiology. AMP-DNM treatment of obese mice improves the status of adipose tissue in many aspects, including a prominent reduction of inflammation (van Eijk et al., 2009). The treatment also leads to decreased iNKT cell activation in adipose tissue of lean mice (Rakhshandehroo et al., 2019).

\section{Fungal GlcCer and GCS as Target}

Fungal infections (cryptococcosis, candidiasis, aspergillosis, and pneumocystosis) are clinically highly relevant. Shortcomings of current anti-fungal drugs are toxicity and drug resistance. Moreover, not all fungi respond to particular drugs. A recently recognized universal target for combatting fungi is GlcCer (Rollin-Pinheiro et al., 2016; Fernandes et al., 2018). This lipid proves to be crucial for the virulence of pathogenic fungi in plants and man. The latter include C. albicans, Cryptococcus neoformans, and Aspergillus fumigatus. GlcCer is in particular critical for survival of fungi in neutral and alkaline environments. Indeed, antibodies to fungal GlcCer were found to exert antifungal effects at such conditions. More recently, desired lowering of fungal GlcCer can be reached by reducing the biosynthesis of the lipid. Well tolerated acylhydrazones have been identified as specific inhibitors of fungal GCS, an enzyme that fundamentally differs from the mammalian counterpart and that is not inhibited by acylhydrazones (Lazzarini et al., 2018; Mor et al., 2018). Pharmaceutical reduction of fungal GlcCer is now envisioned as new opportunity to combat fungal infections, including cryptococcosis.

\section{Neuraminidase Inhibitors as Anti-influenza Viral Agents}

In the 1990's inhibitors of neuraminidase have been designed for prophylaxis and treatment of influenza. The surface envelope of the influenza virus contains the glycoproteins hemagglutinin and neuraminidase. Hemagglutinin mediates viral attachment to the cell surface receptor containing a terminal $\mathrm{N}$-acetylneuraminic acid residue attached $\alpha$-(King, 1956; Merrill, 2011) or $\alpha$-(King, 1956; Gault et al., 2010) to a galactose. By a variety of techniques, like thin-layer chromatography overlay assays and mass spectrometry, the nature of lipid receptors has been identified (Meisen et al., 2012; Hidari et al., 2013). The viral neuraminidase is essential for timely release of the virus from the cellular anchor. The neuraminidase inhibitors zanamivir, laninamivir, oseltamivir, and peramivir have been shown to be effective against most influenza strains, but resistance to specific drugs has developed in some cases (Dobson et al., 2015; Laborda et al., 2016). Some of the neuraminidase inhibitors are also employed as useful research tools in investigations on ganglioside biology (Crain and Shen, 2004; Moore et al., 2007). Total internal reflection fluorescence microscopy has been recently successfully employed to investigate the interaction of viruses with ganglioside containing lipid bilayers, the importance of hemagglutinin and neuraminidase in the process and the inhibitory action of zanamivir (Müller et al., 2019).

\section{FUTURE LIPIDOMICS CHALLENGES}

The investigation of lipids has been historically complicated by their intrinsic hydrophobic features and heterogeneous nature. The recent progress in quantitative mass spectrometric detection of lipids has, however, opened a new world for 
lipidomics. This field is rapid advancing (see Han and Gross, 2003 for an excellent review on the topic). In particular ESI (electrospray ionization) and MALDI (matrix assisted laser desorption/ionization) mass spectrometry methods are nowadays successfully applied in lipidomics (Wang et al., 2019). Besides targeted measurement of specific lipids with MRM (multiple reaction monitoring), non-targeted approaches like shotgun and multi-dimensional lipidomics are increasingly employed (for a recent review on the topic see Bilgin et al., 2016). Improvements have been made in lipid extraction methods (Cruz et al., 2016; Löfgren et al., 2016) and internal standards, such as isotope encoded analogs, become increasingly available (Wisse et al., 2015; Mirzaian et al., 2016; Wang et al., 2017). Derivatization or deacylation of specific lipids may assist their quantitative detection (Mirzaian et al., 2017; $\mathrm{Ma}$ et al., 2019). An important new development is the availability of techniques to study the biology of lipids in living cells. Fluorescent NBD and BODIPY tagged lipids have been used in first generation cell biological investigations and in recent times advances have been made in the generation of photoactivatable, caged, photo-switchable, and tri-functional lipid derivatives assisting the imaging of lipids (reviewed in Laguerre and Schultz, 2018). The spatio-temporal detection of endogenous lipids in cells and tissues still remains a major challenge. QQImaging mass spectrometry (IMS) aims to visualize the location and distribution of metabolites in intact biological samples (see Parrot et al., 2018 for a recent review). One of the ISM techniques employs desorption electrospray ionization (DESI) (Parrot et al., 2018). Minimally destructive DESI-IMS chemical screening is achieved at the $\mu \mathrm{m}$-scale resolution. Alternatively, MALDI-MS imaging is used to detect locally lipids, including GSLs (Vens-Cappell et al., 2016; Jones et al., 2017; Caughlin et al., 2018; Hunter et al., 2018; Sugiyama and Setou, 2018; Tobias et al., 2018; Enomoto et al., 2019). A new development forms the technology for in situ visualization of enzymes involved in glycosphingolipid metabolism. Designed have been fluorescent activity-based probes that covalently label and visualize - active enzyme molecules through covalent linkage to catalytic nucleophile residues. An example in this direction is the enzyme glucocerebrosidase for which probes have been developed allowing in situ monitoring of active enzyme molecules (Witte et al., 2010; Kallemeijn et al., 2012; van Meel et al., 2019).

\section{PERSPECTIVES}

Clinical and laboratory research over many decades has revealed that various pathogens require GSLs of host cells for infection. Thus, the modulation of such lipids in host cells could a priori be considered as treatment for infection control. An obvious provision for such approach is that it does no harm. Any significant reduction of GSLs has been considered for a long time to yield considerable side-effects, likely translating in severe symptoms. The long-term outcome of treatment of patients suffering from GD with agents that reduce GSLs is, however, remarkably positive. No major side-effects are observed in individuals treated for a number of years (Mistry et al., 2018; Lewis and Gaemers, 2019). So far, the agents used do not achieve significant reduction in GSLs in the brain, however, a new generation of compounds aiming at that is being tested at the moment. The near future will learn whether it is feasible to safely reduce GSLs in cells and tissues, including the brain. Next it will have to be established whether such reductions are indeed effective for infection control.

Enormous progress has been made in knowledge on the role of GSLs in various kinds of infection and the immune system's response to this. At this moment much of the knowledge is still descriptive and little translation to preventing and/or treating infections has been accomplished. Genetics and genomics may not provide answers to all questions. It remains essential to acquire fundamental insight on metabolism of GSLs in these gene-oriented times. Such insight will essentially contribute to the design/development of suitable agents than can subtly modulate GSLs as desired for infection control.

This review focusses on pharmacological ways to reduce GSL levels. A fundamentally different approach to target GSLpathogen interactions that has also been conceived is the design of potent carbohydrate-type competitors of bacterial adhesion (Schengrund, 2003; Pieters, 2011). Such approach copies more or less the presumed protective effects of oligosaccharides in milk during the colonization of the intestine.

In conclusion, the coming years should reveal whether GSLs may act as valuable target in infection control.

\section{AUTHOR CONTRIBUTIONS}

All authors contributed to writing the review and preparing figures.

\section{FUNDING}

Research on GSL was funded by NWO, Netherlands (NWOBBOL, grant GlcCer, JA).

\section{ACKNOWLEDGMENTS}

The authors acknowledge the longstanding collaboration with their colleagues, in particular Prof. Herman Overkleeft and Prof. Gijs van der Marel, in the Leiden Institute of Chemistry as well as their collaboration with researchers in the Lysosomal Disease Unit of the Academic Medical Center in Amsterdam. The support over many years by members of Dutch Gaucher disease patient's society is greatly appreciated. Research on glycosphingolipids in health and disease is presently supported by a grant to JA from NWO (Building Blocks of Life: GlcCer). 


\section{REFERENCES}

Aerts, J. M., Hollak, C. E., Boot, R. G., Groener, J. E., and Maas, M. (2006). Substrate reduction therapy of glycosphingolipid storage disorders. J. Inherit. Metab. Dis. 29, 449-456. doi: 10.1007/s10545-006-0272-5

Aerts, J. M., Ottenhoff, R., Powlson, A. S., Grefhorst, A., van Eijk, M., Dubbelhuis, P. F., et al. (2007). Pharmacological inhibition of glucosylceramide synthase enhances insulin sensitivity. Diabetes Metab. Res. Rev. 56, 1341-1349. doi: 10. 2337/db06-1619

Aerts, J. M., van Breemen, M. J., Bussink, A. P., Ghauharali, K., Sprenger, R., Boot, R. G., et al. (2008). Biomarkers for lysosomal storage disorders: identification and application as exemplified by chitotriosidase in Gaucher disease. Acta Paediatr. 97, 7-14. doi: 10.1111/j.1651-2227.2007.00641.x

Amaro, M., Šachl, R., Aydogan, G., Mikhalyov, I. I., Vácha, R., and Hof, M. (2016). GM1 ganglioside inhibits $\beta$-Amyloid oligomerization induced by sphingomyelin. Angew. Chem. Int. Ed. Engl. 55, 9411-9415. doi: 10.1002/anie. 201603178

Ashe, K. M., Bangari, D., Li, L., Cabrera-Salazar, M. A., Bercury, S. D., Nietupski, J. B., et al. (2011). Iminosugar-based inhibitors of glucosylceramide synthase increase brain glycosphingolipids and survival in a mouse model of Sandhoff disease. PLoS One 6:e21758. doi: 10.1371/journal.pone.0021758

Becker, K. A., Riethmüller, J., Lüth, A., Döring, G., Kleuser, B., and Gulbins, E. (2010). Acid sphingomyelinase inhibitors normalize pulmonary ceramide and inflammation in cystic fibrosis. Am. J. Respir. Cell Mol. Biol. 42, 716-724. doi: 10.1165/rcmb.2009-0174OC

Belotserkovsky, I., Brunner, K., Pinaud, L., Rouvinski, A., Dellarole, M., Baron, B., et al. (2018). Glycan-Glycan interaction determines Shigella tropism toward human T Lymphocytes. mBio 9, e2309-e2317. doi: 10.1128/mBio.02309-17

Benktander, J., Barone, A., Johansson, M. M., and Teneberg, S. (2018). Helicobacter pylori SabA binding gangliosides of human stomach. Virulence 9, 738-751. doi: 10.1080/21505594.2018.1440171

Berg, R. D., Levitte, S., O’Sullivan, M. P., O’Leary, S. M., Cambier, C. J., Cameron, J., et al. (2016). Lysosomal disorders drive susceptibility to tuberculosis by compromising macrophage migration. Cell 165, 139-152. doi: 10.1016/j.cell. 2016.02.034

Beutler, E., and Grabowski, G. A. (2001). "Glucosylceramide lipidosis-gaucher disease," in The Metabolic and Molecular Bases of Inherited Diseases, 8th Edn, eds C. R. Scriver, A. L. Beaudet, W. S. Sly, and D. Valle, (NewYork, NY: McGraw-Hill)

Bijl, N., Sokolović, M., Vrins, C., Langeveld, M., Moerland, P. D., Ottenhoff, R., et al. (2009). Modulation of glycosphingolipid metabolism significantly improves hepatic insulin sensitivity and reverses hepatic steatosis in mice. Hepatology 50, 1431-1441. doi: 10.1002/hep.23175

Bilgin, M., Born, P., Fezza, F., Heimes, M., Mastrangelo, N., Wagner, N., et al. (2016). Lipid discovery by combinatorial screening and untargeted LC-MS/MS. Sci. Rep. 6:27920. doi: 10.1038/srep27920

Boas, F. E. (2000). Linkage to Gaucher mutations in the Ashkenazi population: effect of drift on decay of linkage disequilibrium and evidence for heterozygote selection. Blood Cells Mol. Dis. 26, 348-359. doi: 10.1006/bcmd.2000.0314

Boot, R. G., Verhoek, M., de Fost, M., Hollak, C. E., Maas, M., Bleijlevens, B., et al. (2004). Marked elevation of the chemokine CCL18/PARC in Gaucher disease: a novel surrogate marker for assessing therapeutic intervention. Blood 103, 33-39. doi: 10.1182/blood-2003-05-1612

Boot, R. G., Verhoek, M., Donker-Koopman, W., Strijland, A., van Marle, J., Overkleeft, H. S., et al. (2007). Identification of the non-lysosomal glucosylceramidase as beta-glucosidase 2. J. Biol. Chem. 282, 1305-1312. doi: 10.1074/jbc.M610544200

Boven, L. A., van Meurs, M., Boot, R. G., Mehta, A., Boon, L., Aerts, J. M., et al. (2004). Gaucher cells demonstrate a distinct macrophage phenotype and resemble alternatively activated macrophages. Am. J. Clin. Pathol. 122, 359-369. doi: 10.1309/BG5V-A8JR-DQH1-M7HN

Brady, R. O. (2003). Enzyme replacement therapy: conception, chaos and culmination. Philos. Trans. R. Soc. Lond. B Biol. Sci. 358, 915-919. doi: 10.1098/ rstb.2003.1269

Brady, R. O., Kanfer, J. N., Bradley, R. M., and Shapiro, D. (1966). Demonstration of a deficiency of glucocerebroside-cleaving enzyme in Gaucher's disease. J. Clin. Invest. 45, 1112-1115. doi: 10.1172/JCI105417
Breiden, B., and Sandhoff, K. (2019). Lysosomal glycosphingolipid storage diseases. Annu. Rev. Biochem. 88, 461-485. doi: 10.1146/annurev-biochem-013118111518

Brennan, M. J., Hannah, J. H., and Leininger, E. (1991). Adhesion of Bordetella pertussis to sulfatides and to the GalNAc beta $4 \mathrm{Gal}$ sequence found in glycosphingolipids. J. Biol. Chem. 266, 18827-18831.

Bussink, A. P., van Eijk, M., Renkema, G. H., Aerts, J. M., and Boot, R. G. (2006). The biology of the Gaucher cell: the cradle of human chitinases. Int. Rev. Cytol. 252, 71-128. doi: 10.1016/S0074-7696(06)52001-7

Carlson, R. O., Masco, D., Brooker, G., and Spiegel, S. (1994). Endogenous ganglioside GM1 modulates L-type calcium channel activity in N18 neuroblastoma cells. J. Neurosci. 14, 2272-2281. doi: 10.1523/JNEUROSCI.1404-02272.1994

Caughlin, S., Maheshwari, S., Agca, Y., Agca, C., Harris, A. J., Jurcic, K., et al. (2018). Membrane-lipid homeostasis in a prodromal rat model of Alzheimer's disease: characteristic profiles in ganglioside distributions during aging detected using MALDI imaging mass spectrometry. Biochim. Biophys. Acta Gen. Subj. 1862, 1327-1338. doi: 10.1016/j.bbagen.2018.03.011

Chung, H. Y., Witt, C. J., Hurtado-Oliveros, J., Wickel, J., Gräler, M. H., Lupp, A., et al. (2018). Acid sphingomyelinase inhibition stabilizes hepatic ceramide content and improves hepatic biotransformation capacity in a murine model of polymicrobial sepsis. Int. J. Mol. Sci. 19:E3163. doi: 10.3390/ijms19103163

Colombo, R. (2000). Age estimate of the N370S mutation causing Gaucher disease in Ashkenazi Jews and European populations: a reappraisal of haplotype data. Am. J. Genet. 66, 692-697. doi: 10.1086/302757

Coskun, Ü, Grzybek, M., Drechsel, D., and Simons, K. (2011). Regulation of human EGF receptor by lipids. Proc. Natl. Acad. Sci. U.S.A. 108, 9044-9048. doi: 10.1073/pnas.1105666108

Cox, T. M., and Cachón-González, M. B. (2012). The cellular pathology of lysosomal diseases. J. Pathol. 226, 241-254. doi: 10.1002/path.3021

Crain, S. M., and Shen, K. F. (2004). Neuraminidase inhibitor, oseltamivir blocks GM1 ganglioside-regulated excitatory opioid receptor-mediated hyperalgesia, enhances opioid analgesia and attenuates tolerance in mice. Brain Res. 995, 260-266. doi: 10.1016/j.brainres.2003.09.068

Cruz, M., Wang, M., Frisch-Daiello, J., and Han, X. (2016). Improved butanolmethanol (BUME) method by replacing acetic acid for lipid extraction of biological samples. Lipids 51, 887-896. doi: 10.1007/s11745-016-4164-7

Cuatrecasas, P. (1973a). Gangliosides and membrane receptors for cholera toxin Biochemistry 12, 3558-3566. doi: 10.1021/bi00742a032

Cuatrecasas, P. (1973b). Vibrio cholerae choleragenoid. Mechanism of inhibition of cholera toxin action. Biochemistry 12, 3577-3581. doi: 10.1021/bi00742a034

D’Angelo, G., Capasso, S., Sticco, L., and Russo, D. (2013). Glycosphingolipids: synthesis and functions. FEBS J. 280, 6338-6353. doi: 10.1111/febs.12559

de Bentzmann, S., Roger, P., Dupuit, F., Bajolet-Laudinat, O., Fuchey, C., Plotkowski, M. C., et al. (1996). Asialo GM1 is a receptor for Pseudomonas aeruginosa adherence to regenerating respiratory epithelial cells. Infect. Immun. $64,1582-1588$.

Dekker, N., van Dussen, L., Hollak, C. E., Overkleeft, H., Scheij, S., Ghauharali, K., et al. (2011). Elevated plasma glucosylsphingosine in Gaucher disease: relation to phenotype, storage cell markers, and therapeutic response. Blood 118, e118-e127. doi: 10.1182/blood-2011-05-352971

Di Rosa, M., Distefano, G., Zorena, K., and Malaguarnera, L. (2016). Chitinases and immunity: ancestral molecules with new functions. Immunobiology 221, 399-411. doi: 10.1016/j.imbio.2015.11.014

Diamond, J. M. (1994). Human genetics. Jewish lysosomes. Nature 368, 291-292. doi: $10.1038 / 368291 \mathrm{a} 0$

Diaz, G. A., Gelb, B. D., Risch, N., Nygaard, T. G., Frisch, A., Cohen, I. J., et al. (2000). Gaucher disease: the origins of the Ashkenazi Jewish N370S and 84GG acid beta-glucosidase mutations. Am. J. Hum. Genet. 66, 1821-1832. doi: 10. $1086 / 302946$

Dobson, J., Whitley, R. J., Pocock, S., and Monto, A. S. (2015). Oseltamivir treatment for influenza in adults: a meta-analysis of randomised controlled trials. Lancet 385, 1729-1737. doi: 10.1016/S0140-6736(14)62449-1

Enomoto, H., Takeda, S., Hatta, H., and Zaima, N. (2019). Tissue-specific distribution of sphingomyelin species in pork chop revealed by matrix-assisted laser desorption/ionization-imaging mass spectrometry. J. Food Sci. 84, 1758 1763. doi: 10.1111/1750-3841.14667 
Fabrias, G., Muñoz-Olaya, J., Cingolani, F., Signorelli, P., Casas, J., Gagliostro, V., et al. (2012). Dihydroceramide desaturase and dihydrosphingolipids: debutant players in the sphingolipid arena. Prog. Lipid Res. 51, 82-94. doi: 10.1016/j. plipres.2011.12.002

Feingold, K. R., and Elias, P. M. (2014). Role of lipids in the formation and maintenance of the cutaneous permeability barrier. Biochim. Biophys. Acta 1841, 280-294. doi: 10.1016/j.bbalip.2013.11.007

Fernandes, C. M., Goldman, G. H., and Del Poeta, M. (2018). Biological roles played by sphingolipids in dimorphic and filamentous fungi. mBio 9:e00642-18. doi: $10.1128 / \mathrm{mBio} .00642-18$

Ferraz, M. J., Kallemeijn, W. W., Mirzaian, M., Herrera Moro, D., Marques, A., Wisse, P., et al. (2014). Gaucher disease and Fabry disease: new markers and insights in pathophysiology for two distinct glycosphingolipidoses. Biochim. Biophys. Acta 1841, 811-825. doi: 10.1016/j.bbalip.2013.11.004

Ferraz, M. J., Marques, A. R., Appelman, M. D., Verhoek, M., Strijland, A., Mirzaian, M., et al. (2016). Lysosomal glycosphingolipid catabolism by acid ceramidase: formation of glycosphingoid bases during deficiency of glycosidases. FEBS Lett. 590, 716-725. doi: 10.1002/1873-3468.12104

Gault, C. R., Obeid, L. M., and Hannun, Y. A. (2010). An overview of sphingolipid metabolism: from synthesis to breakdown. Adv. Exp. Med. Biol. 688, 1-23. doi: 10.1007/978-1-4419-6741-1_1

Ghauharali-van der Vlugt, K., Langeveld, M., Poppema, A., Kuiper, S., Hollak, C. E., Aerts, J. M., et al. (2008). Prominent increase in plasma ganglioside GM3 is associated with clinical manifestations of type I Gaucher disease. Clin. Chim. Acta 389, 109-113. doi: 10.1016/j.cca.2007.12.001

Ghisaidoobe, A. T., van den Berg, R. J., Butt, S. S., Strijland, A., Donker-Koopman, W. E., Scheij, S., et al. (2014). Identification and development of biphenyl substituted iminosugars as improved dual glucosylceramide synthase/neutral glucosylceramidase inhibitors. J. Med. Chem. 57, 9096-9104. doi: 10.1021/ jm501181z

Goodfellow, J. A., and Willison, H. J. (2018). Gangliosides and autoimmune peripheral nerve diseases. Prog. Mol. Biol. Transl. Sci. 156, 355-382. doi: 10. 1016/bs.pmbts.2017.12.010

Grassmé, H., Riethmüller, J., and Gulbins, E. (2007). Biological aspects of ceramideenriched membrane domains. Prog. Lipid Res. 46, 161-170. doi: 10.1016/j. plipres.2007.03.002

Gulbins, E., and Grassmé, H. (2002). Ceramide and cell death receptor clustering. Biochim. Biophys. Acta 1585, 139-145. doi: 10.1016/s1388-1981(02)00334-7

Han, X., and Gross, R. W. (2003). Global analyses of cellular lipidomes directly from crude extracts of biological samples by ESI mass spectrometry: a bridge to lipidomics. J. Lipid Res. 44, 1071-1079. doi: 10.1194/jlr.r300004-jlr200

Hanada, K. (2005). Sphingolipids in infectious diseases. Jpn. J. Infect. Dis. 58, 131-148.

Hanada, K., Kumagai, K., Tomishige, N., and Yamaji, T. (2009). CERT-mediated trafficking of ceramide. Biochim. Biophys. Acta 1791, 684-691. doi: 10.1016/j. bbalip.2009.01.006

Hanada, K., Kumagai, K., Yasuda, S., Miura, Y., Kawano, M., Fukasawa, M., et al. (2003). Molecular machinery for non-vesicular trafficking of ceramide. Nature 426, 803-809. doi: 10.1038/nature02188

Hidari, K. I., Yamaguchi, M., Ueno, F., Abe, T., Yoshida, K., and Suzuki, T. (2013). Influenza virus utilizes N-linked sialoglycans as receptors in A549 cells. Biochem. Biophys. Res. Commun. 436, 394-399. doi: 10.1016/j.bbrc.2013. 05.112

Hirst, T. R., Fraser, S., Soriani, M., Aman, A. T., de, H. L., Hearn, A., et al. (2002). New insights into the structure-function relationships and therapeutic applications of cholera-like enterotoxins. Int. J. Med. Microbiol. 291, 531-535. doi: 10.1078/1438-4221-00163

Hollak, C. E., Levi, M., Berends, F., Aerts, J. M., and van Oers, M. H. (1997). Coagulation abnormalities in type 1 Gaucher disease are due to low-grade activation and can be partly by enzyme supplementation therapy. Br. J. Haematol. 96, 470-476. doi: 10.1046/j.1365-2141.1997.d01-2076.x

Hollak, C. E., van Weely, S., van Oers, M. H., and Aerts, J. M. (1994). Marked elevation of plasma chitotriosidase activity. A novel hallmark of Gaucher disease. J. Clin. Invest. 93, 1288-1292. doi: 10.1172/JCI117084

Hose, M., Günther, A., Abberger, H., Begum, S., Korencak, M., Becker, K. A., et al. (2019). T cell-specific overexpression of acid sphingomyelinase results in elevated t cell activation and reduced parasitemia during Plasmodium yoelii infection. Front. Immunol. 10:1225. doi: 10.3389/fimmu.2019.01225
Hunter, M., Demarais, N. J., Faull, R. L. M., Grey, A. C., and Curtis, M. A. (2018). Layer-specific lipid signatures in the human subventricular zone demonstrated by imaging mass spectrometry. Sci. Rep. 8:2551. doi: 10.1038/s41598-01820793-4

Hyun, C. S., and Kimmich, G. A. (1984). Interaction of cholera toxin and Escherichia coli enterotoxin with isolated intestinal epithelial cells. Am. J. Physiol. 247, G623-G631. doi: 10.1152/ajpgi.1984.247.6.G623

Ichikawa, S., Sakiyama, H., Suzuki, G., Hidari, K. I., and Hirabayashi, Y. (1996). Expression cloning of a cDNA for human ceramide glucosyltransferase that catalyzes the first glycosylation step of glycosphingolipid synthesis. Proc. Natl. Acad. Sci. U.S.A. 93, 4638-4643. doi: 10.1073/pnas.93.10.4638

Inokuchi, J., Nagafuku, M., Ohno, I., and Suzuki, A. (2015). Distinct selectivity of gangliosides required for $\mathrm{CD} 4^{+} \mathrm{T}$ and $\mathrm{CD} 8^{+} \mathrm{T}$ cell activation. Biochim. Biophys. Acta 1851, 98-106. doi: 10.1016/j.bbalip.2014.07.013

Inokuchi, J. I., Inamori, K. I., Kabayama, K., Nagafuku, M., Uemura, S., Go, S., et al. (2018). Biology of GM3 Ganglioside. Prog. Mol. Biol. Transl. Sci. 156, 151-195. doi: 10.1016/bs.pmbts.2017.10.004

Iwabuchi, K., and Nagaoka, I. (2002). Lactosylceramide-enriched glycosphingolipid signaling domain mediates superoxide generation from human neutrophils. Blood 100, 1454-1464. doi: 10.1182/blood.v100.4.1454. h81602001454_1454_1464

Iyer, A., van Eijk, M., Silva, E., Hatta, M., Faber, W., Aerts, J. M., et al. (2009). Increased chitotriosidase activity in serum of leprosy patients: association with bacillary leprosy. Clin. Immunol. 131, 501-509. doi: 10.1016/j.clim.2009.02.003

Jolivet-Reynaud, C., Hauttecoeur, B., and Alouf, J. E. (1989). Interaction of Clostridium perfringens delta toxin with erythrocyte and liposome membranes and relation with the specific binding to the ganglioside GM2. Toxicon 27, 1113-1126. doi: 10.1016/0041-0101(89)90005-6

Jones, E. E., Zhang, W., Zhao, X., Quiason, C., Dale, S., Shahidi-Latham, S., et al. (2017). Tissue localization of glycosphingolipid accumulation in a Gaucher disease mouse brain by LC-ESI-MS/MS and high-resolution MALDI imaging mass spectrometry. SLAS Discov. 22, 1218-1228. doi: 10.1177/ 2472555217719372

Kabayama, K., Sato, T., Saito, K., Loberto, N., Prinetti, A., Sonnino, S., et al. (2007). Dissociation of the insulin receptor and caveolin-1 complex by ganglioside GM3 in the state of insulin resistance. Proc. Natl. Acad. Sci. U.S.A. 104, 13678-13683. doi: 10.1073/pnas.0703650104

Kallemeijn, W. W., Li, K. Y., Witte, M. D., Marques, A. R., Aten, J., Scheij, S., et al. (2012). Novel activity-based probes for broad-spectrum profiling of retaining $\beta$-exoglucosidases in situ and in vivo. Angew. Chem. Int. Ed. Engl. 51, 12529-12533. doi: 10.1002/anie.201207771

Källenius, G., Möllby, R., Svenson, S. B., Winberg, J., and Hultberg, H. (1980). Identification of a carbohydrate receptor recognized by uropathogenic Escherichia coli. Infection 8(Suppl. 3), 288-293. doi: 10.1007/BF01639597

Kidani, Y., and Bensinger, S. J. (2014). Lipids rule: resetting lipid metabolism restores $\mathrm{T}$ cell function in systemic lupus erythematosus. J. Clin. Invest. 124, 482-485. doi: 10.1172/JCI74141

King, H. (1956). Sigmund Otto Rosenheim: 1871-1955. Biograph. Mem. Fellows R. Soc. 2, 257-267.

Kitamura, M., Takamiya, K., Aizawa, S., Furukawa, K., and Furukawa, K. (1999). Gangliosides are the binding substances in neural cells for tetanus and botulinum toxins in mice. Biochim. Biophys. Acta 1441, 1-3. doi: 10.1016/s13881981(99)00140-7

Klokk, T. I., Kavaliauskiene, S., and Sandvig, K. (2016). Cross-linking of glycosphingolipids at the plasma membrane: consequences for intracellular signaling and traffic. Cell Mol. Life Sci. 73, 1301-1316. doi: 10.1007/s00018-0152049-1

Koprivica, V., Stone, D. L., Park, J. K., Callahan, M., Frisch, A., Cohen, I. J., et al. (2000). Analysis and classification of 304 mutant alleles in patients with type 1 and type 3 Gaucher disease. Am. J. Hum. Genet. 66, 1777-1786. doi: $10.1086 / 302925$

Kościelak, J. (2012). The hypothesis on function of glycosphingolipids and ABO blood groups revisited. Neurochem. Res. 37, 1170-1184. doi: 10.1007/s11064012-0734-0

Kramer, G., Wegdam, W., Donker-Koopman, W., Ottenhoff, R., Gaspar, P., Verhoek, M., et al. (2016). Elevation of glycoprotein nonmetastatic melanoma protein B in type 1 Gaucher disease patients and mouse models. FEBS Open Biol. 6, 902-913. doi: 10.1002/2211-5463.12078 
Krivan, H. C., Olson, L. D., Barile, M. F., Ginsburg, V., and Roberts, D. D. (1989). Adhesion of Mycoplasma pneumoniae to sulfated glycolipids and inhibition by dextran sulfate. J. Biol. Chem. 264, 9283-9288.

Kumar, A., Suryadevara, N., Hill, T. M., Bezbradica, J. S., Van Kaer, L., and Joyce, S. (2017). Natural killer T cells: an ecological evolutionary developmental biology perspective. Front. Immunol. 8:1858. doi: 10.3389/fimmu.2017.01858

Kuziemko, G. M., Stroh, M., and Stevens, R. C. (1996). Cholera toxin binding affinity and specificity for gangliosides determined by surface plasmon resonance. Biochemistry 35, 6375-6384. doi: 10.1021/bi952314i

Laborda, P., Wang, S. Y., and Voglmeir, J. (2016). Influenza neuraminidase inhibitors: synthetic approaches, derivatives and biological activity. Molecules 21:E1513.

Laguerre, A., and Schultz, C. (2018). Novel lipid tools and probes for biological investigations. Curr. Opin. Cell Biol. 53, 97-104. doi: 10.1016/j.ceb.2018.06.013

Langeveld, M., and Aerts, J. M. (2009). Glycosphingolipids and insulin resistance. Prog. Lipid Res. 48, 196-205. doi: 10.1016/j.plipres.2009.03.002

Langeveld, M., Ghauharali, K. J., Sauerwein, H. P., Ackermans, M. T., Groener, J. E., Hollak, C. E., et al. (2008). Type I Gaucher disease, a glycosphingolipid storage disorder, is associated with insulin resistance. J. Clin. Endocrinol. Metab. 93, 845-851. doi: 10.1210/jc.2007-1702

Lazzarini, C., Haranahalli, K., Rieger, R., Ananthula, H. K., Desai, P. B., Ashbaugh, A., et al. (2018). Acylhydrazones as antifungal agents targeting the synthesis of fungal sphingolipids. Antimicrob. Agents Chemother. 62:e00156-18. doi: 10. 1128/AAC.00156-18

Leffler, H., and Svanborg-Edén, C. (1981). Glycolipid receptors for uropathogenic Escherichia coli on human erythrocytes and uroepithelial cells. Infect. Immun. 34, 920-929.

Lewis, G., and Gaemers, S. J. M. (2019). Long-term adverse event profile from four completed trials of oral eliglustat in adults with Gaucher disease type 1. Orphanet. J. Rare Dis. 14:128. doi: 10.1186/s13023-019-1085-6

Li, C., Wang, A., Wu, Y., Gulbins, E., Grassmé, H., and Zhao, Z. (2019). Acid sphingomyelinase-ceramide system in bacterial infections. Cell Physiol. Biochem. 52, 280-301. doi: 10.33594/000000021

Li, T. A., and Schnaar, R. L. (2018). Congenital disorders of ganglioside biosynthesis. Prog. Mol. Biol. Transl. Sci. 156, 63-82. doi: 10.1016/bs.pmbts. 2018.01.001

Lingwood, C. A. (1996). Role of verotoxin receptors in pathogenesis. Trends Microbiol. 4, 147-153. doi: 10.1016/0966-842X(96)10017-2

Lingwood, C. A., and Branch, D. R. (2011). The role of glycosphingolipids in HIV/AIDS. Discov. Med. 11, 303-313.

Lingwood, D., and Simons, K. (2010). Lipid rafts as a membrane-organizing principle. Science 327, 46-50. doi: 10.1126/science.1174621

Löfgren, L., Forsberg, G. B., and Ståhlman, M. (2016). The BUME method: a new rapid and simple chloroform-free method for total lipid extraction of animal tissue. Sci. Rep. 6:27688. doi: 10.1038/srep27688

Lombardo, E., van Roomen, C. P., van Puijvelde, G. H., Ottenhoff, R., van Eijk, M., Aten, J., et al. (2012). Correction of liver steatosis by a hydrophobic iminosugar modulating glycosphingolipids metabolism. PLoS One 7:e38520. doi: 10.1371/ journal.pone.0038520

Lopez, P. H. H., and Báez, B. B. (2018). Gangliosides in axon stability and regeneration. Prog. Mol. Biol. Transl. Sci. 156, 383-412. doi: 10.1016/bs.pmbts. 2018.03.001

Lund, N., Olsson, M. L., Ramkumar, S., Sakac, D., Yahalom, V., Levene, C., et al. (2009). The human $\mathrm{P}(\mathrm{k})$ histo-blood group antigen provides protection against HIV-1 infection. Blood 113, 4980-4991. doi: 10.1182/blood-2008-03-143396

Ma, H. F., Wei, F., Wu, B. F., Yang, C., Xie, Y., Wu, Z. Y., et al. (2019). Profiling and quantification of aminophospholipids based on chemical derivatization coupled with HPLC-MS. J. Lipid Res. 60, 121-134. doi: 10.1194/jlr.M089482

Mahdavi, J., Sondén, B., Hurtig, M., Olfat, F. O., Forsberg, L., Roche, N., et al. (2002). Helicobacter pylori SabA adhesin in persistent infection and chronic inflammation. Science 297, 573-578. doi: 10.1126/science.1069076

Marques, A. R., Aten, J., Ottenhoff, R., van Roomen, C. P., Herrera Moro, D., Claessen, N., et al. (2015). Reducing GBA2 activity ameliorates neuropathology in niemann-pick type C mice. PLoS One 10:e0135889. doi: 10.1371/journal. pone. 0135889

Marques, A. R., Mirzaian, M., Akiyama, H., Wisse, P., Ferraz, M. J., Gaspar, P., et al. (2016). Glucosylated cholesterol in mammalian cells and tissues: formation and degradation by multiple cellular $\beta$-glucosidases. J. Lipid Res. 57, 451-463. doi: 10.1194/jlr.M064923

Marshall, J., Nietupski, J. B., Park, H., Cao, J., Bangari, D. S., Silvescu, C., et al. (2019). Substrate reduction therapy for sandhoff disease through inhibition of glucosylceramide synthase activity. Mol. Ther. 27, 1495-1506. doi: 10.1016/j. ymthe.2019.05.018

Martín-Martín, A. I., Vizcaíno, N., and Fernández-Lago, L. (2010). Cholesterol, ganglioside GM1 and class A scavenger receptor contribute to infection by Brucella ovis and Brucella canis in murine macrophages. Microbes Infect. 12, 246-251. doi: 10.1016/j.micinf.2009.12.008

Masserini, M., Freire, E., Palestini, P., Calappi, E., and Tettamanti, G. (1992). Fuc-GM1 ganglioside mimics the receptor function of GM1 for cholera toxin. Biochemistry 31, 2422-2426. doi: 10.1021/bi00123a030

McDonald, G., Deepak, S., Miguel, L., Hall, C. J., Isenberg, D. A., Magee, A. I., et al. (2014). Normalizing glycosphingolipids restores function in CD4+ T cells from lupus patients. J. Clin. Invest. 124, 712-724. doi: 10.1172/JCI69571

Meijer, A. H., and Aerts, J. M. (2016). Linking smokers' susceptibility to tuberculosis with lysosomal storage disorders. Dev. Cell 37, 112-113. doi: 10. 1016/j.devcel.2016.04.004

Meiners, J., Palmieri, V., Klopfleisch, R., Ebel, J. F., Japtok, L., Schumacher, F., et al. (2019). Intestinal acid sphingomyelinase protects from severe pathogen-driven colitis. Front. Immunol. 10:1386. doi: 10.3389/fimmu.2019.01386

Meisen, I., Dzudzek, T., Ehrhardt, C., Ludwig, S., Mormann, M., Rosenbrück, R., et al. (2012). The human H3N2 influenza viruses A/Victoria/3/75 and A/Hiroshima/52/2005 preferentially bind to $\alpha 2$-3-sialylated monosialogangliosides with fucosylated poly-N-acetyllactosaminyl chains. Glycobiology 22, 1055-1076. doi: 10.1093/glycob/cws077

Merrill, A. H. Jr., and Sullards, M. C. (2017). Opinion article on lipidomics: inherent challenges of lipidomic analysis of sphingolipids. Biochim. Biophys. Acta Mol. Cell Biol. Lipids 1862, 774-776. doi: 10.1016/j.bbalip.2017.01.009

Merrill, A. H. (2011). Sphingolipid and glycosphingolipid metabolic pathways in the era of sphingolipidomics. Chem. Rev. 111, 6387-6422. doi: 10.1021/ cr2002917

Mirzaian, M., Wisse, P., Ferraz, M. J., Gold, H., Donker-Koopman, W. E., Verhoek, M., et al. (2015). Mass spectrometric quantification of glucosylsphingosine in plasma and urine of type 1 Gaucher patients using an isotope standard. Blood Cells Mol. Dis. 54, 307-314. doi: 10.1016/j.bcmd.2015.01.006

Mirzaian, M., Wisse, P., Ferraz, M. J., Marques, A. R. A., Gabriel, T. L., van Roomen, C. P. A. A., et al. (2016). Accurate quantification of sphingosine-1-phosphate in normal and Fabry disease plasma, cells and tissues by LC-MS/MS with (13)C-encoded natural S1P as internal standard. Clin. Chim. Acta 459, 36-44. doi: 10.1016/j.cca.2016.05.017

Mirzaian, M., Wisse, P., Ferraz, M. J., Marques, A. R. A., Gaspar, P., Oussoren, S. V., et al. (2017). Simultaneous quantitation of sphingoid bases by UPLC-ESIMS/MS with identical (13)C-encoded internal standards. Clin. Chim. Acta 466, 178-184. doi: 10.1016/j.cca.2017.01.014

Mistry, P. K., Balwani, M., Baris, H. N., Turkia, H. B., Burrow, T. A., Charrow, J., et al. (2018). Safety, efficacy, and authorization of eliglustat as a first-line therapy in Gaucher disease type 1. Blood Cells Mol. Dis. 71, 71-74. doi: 10.1016/j.bcmd. 2018.04.001

Mistry, P. K., Liu, J., Sun, L., Chuang, W. L., Yuen, T., Yang, R., et al. (2014). Glucocerebrosidase 2 gene deletion rescues type 1 Gaucher disease. Proc. Natl. Acad. Sci. U.S.A. 111, 4934-4939. doi: 10.1073/pnas.1400768111

Moore, M. L., Chi, M. H., Zhou, W., Goleniewska, K., O’Neal, J. F., Higginbotham, J. N., et al. (2007). Cutting Edge: oseltamivir decreases T cell GM1 expression and inhibits clearance of respiratory syncytial virus: potential role of endogenous sialidase in antiviral immunity. J. Immunol. 178, 2651-2654. doi: 10.4049/jimmunol.178.5.2651

Mor, V., Rella, A., Farnoud, A. M., Singh, A., Munshi, M., Bryan, A., et al. (2018). Identification of a new class of antifungals targeting the synthesis of fungal sphingolipids. mBio 9:e00188-18. doi: 10.1128/mBio.00188-18

Mukai, T., Kaneko, S., Matsumoto, M., and Ohori, H. (2004). Binding of Bifidobacterium bifidum and Lactobacillus reuteri to the carbohydrate moieties of intestinal glycolipids recognized by peanut agglutinin. Int. J. Food Microbiol. 90, 357-362. doi: 10.1016/S0168-1605(03)00317-9

Mukherjee, S., and Maxfield, F. R. (2004). Membrane domains. Annu. Rev. Cell Dev. Biol. 20, 839-866. doi: 10.1146/annurev.cellbio.20.010403.095451 
Müller, M., Lauster, D., Wildenauer, H. H. K., Herrmann, A., and Block, S. (2019). Mobility-based quantification of multivalent virus-receptor interactions: new insights into influenza A virus binding mode. Nano Lett. 19, 1875-1882. doi: 10.1021/acs.nanolett.8b04969

Nagafuku, M., Okuyama, K., Onimaru, Y., Suzuki, A., Odagiri, Y., Yamashita, T., et al. (2012). CD4 and CD8 T cells require different membrane gangliosides for activation. Proc. Natl. Acad. Sci. U.S.A. 109, E336-E342. doi: 10.1073/pnas. 1114965109

Nagata, M., Izumi, Y., Ishikawa, E., Kiyotake, R., Doi, R., Iwai, S., et al. (2017). Intracellular metabolite $\beta$-glucosylceramide is an endogenous Mincle ligand possessing immunostimulatory activity. Proc. Natl. Acad. Sci. U.S.A. 114, E3285-E3294. doi: 10.1073/pnas.1618133114

Nair, S., Boddupalli, C. S., Verma, R., Liu, J., Yang, R., Pastores, G. M., et al. (2015). Type II NKT-TFH cells against Gaucher lipids regulate B-cell immunity and inflammation. Blood 125, 1256-1271. doi: 10.1182/blood-2014-09600270

Nair, S., Branagan, A. R., Liu, J., Boddupalli, C. S., Mistry, P. K., and Dhodapkar, M. V. (2016). Clonal immunoglobulin against lysolipids in the origin of myeloma. N. Engl. J. Med. 374, 555-561. doi: 10.1056/NEJMoa1508808

Nakayama, H., Kurihara, H., Morita, Y. S., Kinoshita, T., Mauri, L., Prinetti, A., et al. (2016). Lipoarabinomannan binding to lactosylceramide in lipid rafts is essential for the phagocytosis of mycobacteria by human neutrophils. Sci. Signal. 9:ra101. doi: 10.1126/scisignal.aaf1585

Nakayama, H., Nagafuku, M., Suzuki, A., Iwabuchi, K., and Inokuchi, J. I. (2018). The regulatory roles of glycosphingolipid-enriched lipid rafts in immune systems. FEBS Lett. 592, 3921-3942. doi: 10.1002/1873-3468.13275

Naroeni, A., and Porte, F. (2002). Role of cholesterol and the ganglioside GM(1) in entry and short-term survival of Brucella suis in murine macrophages. Infect. Immun. 70, 1640-1644. doi: 10.1128/IAI.70.3.1640-1644.2002

Newburg, D. S., and Chaturvedi, P. (1992). Neutral glycolipids of human and bovine milk. Lipids 27, 923-927. doi: 10.1007/BF02535874

Nietupski, J. B., Pacheco, J. J., Chuang, W. L., Maratea, K., Li, L., Foley, J., et al. (2012). Iminosugar-based inhibitors of glucosylceramide synthase prolong survival but paradoxically increase brain glucosylceramide levels in NiemannPick C mice. Mol. Genet. Metab. 105, 621-628. doi: 10.1016/j.ymgme.2012. 01.020

Nihei, W., Nagafuku, M., Hayamizu, H., Odagiri, Y., Tamura, Y., Kikuchi, Y., et al. (2018). NPC1L1-dependent intestinal cholesterol absorption requires ganglioside GM3 in membrane microdomains. J. Lipid Res. 59, 2181-2187. doi: 10.1194/jlr.M089201

Nimrichter, L., Burdick, M. M., Aoki, K., Laroy, W., Fierro, M. A., Hudson, S. A., et al. (2008). E-selectin receptors on human leukocytes. Blood 112, 3744-3752. doi: 10.1182/blood-2008-04-149641

Otnaess, A. B., Laegreid, A., and Ertresvåg, K. (1983). Inhibition of enterotoxin from Escherichia coli and Vibrio cholerae by gangliosides from human milk. Infect. Immun. 40, 563-569. doi: 10.1016/0024-3205(87)90252-9

Pandey, M. K., Burrow, T. A., Rani, R., Martin, L. J., Witte, D., Setchell, K. D., et al. (2017). Complement drives glucosylceramide accumulation and tissue inflammation in Gaucher disease. Nature 543, 108-112. doi: 10.1038/ nature 21368

Parrot, D., Papazian, S., Foil, D., and Tasdemir, D. (2018). Imaging the unimaginable: desorption electrospray ionization - imaging mass spectrometry (DESI-IMS) in natural product research. Planta Med. 84, 584-593. doi: 10.1055/ s-0044-100188

Pei, B., Vela, J. L., Zajonc, D., and Kronenberg, M. (2012). Interplay between carbohydrate and lipid in recognition of glycolipid antigens by natural killer T cells. Ann. N. Y. Acad. Sci. 1253, 68-79. doi: 10.1111/j.1749-6632

Pieters, R. J. (2011). Carbohydrate mediated bacterial adhesion. Adv. Exp. Med. Biol. 715, 227-240. doi: 10.1007/978-94-007-0940-9_14

Platt, F. M. (2014). Sphingolipid lysosomal storage disorders. Nature 510, 68-75. doi: $10.1038 /$ nature13476

Platt, F. M., Jeyakumar, M., Andersson, U., Priestman, D. A., Dwek, R. A., Butters, T. D., et al. (2001). Inhibition of substrate synthesis as a strategy for glycolipid lysosomal storage disease therapy. J. Inherit. Metab. Dis. 24, 275-290. doi: 10.1023/A:1010335505357

Pyne, S., Adams, D. R., and Pyne, N. J. (2016). Sphingosine 1-phosphate and sphingosine kinases in health and disease: recent advances. Prog Lipid Res. 62, 93-106. doi: 10.1016/j.plipres.2016.03.001
Rakhshandehroo, M., van Eijkeren, R. J., Gabriel, T. L., de Haar, C., Gijzel, S. M. W., Hamers, N., et al. (2019). Adipocytes harbor a glucosylceramide biosynthesis pathway involved in iNKT cell activation. Biochim. Biophys. Acta Mol. Cell Biol. Lipids 1864, 1157-1167. doi: 10.1016/j.bbalip.2019.04.016

Rollin-Pinheiro, R., Singh, A., Barreto-Bergter, E., and Del Poeta, M. (2016). Sphingolipids as targets for treatment of fungal infections. Future Med. Chem. 8, 1469-1484. doi: 10.4155/fmc-2016-0053

Sandhoff, R., and Sandhoff, K. (2018). Emerging concepts of ganglioside metabolism. FEBS Lett. 592, 3835-3864. doi: 10.1002/1873-3468.13114

Sandhoff, R., Schulze, H., and Sandhoff, K. (2018). Ganglioside metabolism in health and disease. Prog. Mol. Biol. Transl. Sci. 156, 1-62. doi: 10.1016/bs.pmbts. 2018.01.002

Sato, T., Iwabuchi, K., Nagaoka, I., Adachi, Y., Ohno, N., Tamura, H., et al. (2006). Induction of human neutrophil chemotaxis by Candida albicans-derived beta1,6-long glycoside side-chain-branched beta-glucan. J. Leukoc. Biol. 80, 204211. doi: 10.1189/jlb.0106069

Schengrund, C. L. (2003). "Multivalent" saccharides: development of new approaches for inhibiting the effects of glycosphingolipid-binding pathogens. Biochem. Pharmacol. 65, 699-707. doi: 10.1016/s0006-2952(02)01553-8

Schnaar, R. L. (2004). Glycolipid-mediated cell-cell recognition in inflammation and nerve regeneration. Arch. Biochem. Biophys. 426, 163-172. doi: 10.1016/j. abb.2004.02.019

Schnaar, R. L., and Lopez, P. H. (2009). Myelin-associated glycoprotein and its axonal receptors. J. Neurosci. Res. 87, 3267-3276. doi: 10.1002/jnr.21992

Schuchman, E. H. (2010). Acid sphingomyelinase, cell membranes and human disease: lessons from Niemann-Pick disease. FEBS Lett. 584, 1895-1900. doi: 10.1016/j.febslet.2009.11.083

Schwake, M., Schröder, B., and Saftig, P. (2013). Lysosomal membrane proteins and their central role in physiology. Traffic 14, 739-748. doi: 10.1111/tra.12056

Shayman, J. A., and Larsen, S. D. (2014). The development and use of small molecule inhibitors of glycosphingolipid metabolism for lysosomal storage diseases. J. Lipid Res. 55, 1215-1225. doi: 10.1194/jlr.R047167

Shen, C., Bullens, D., Kasran, A., Maerten, P., Boon, L., Aerts, J. M., et al. (2004). Inhibition of glycolipid biosynthesis by N-(5-adamantane-1-ylmethoxy-pentyl)-deoxynojirimycin protects against the inflammatory response in hapten-induced colitis. Int. Immunopharmacol. 4, 939-951. doi: 10.1016/j. intimp.2004.04.008

Siebert, M., Sidransky, E., and Westbroek, W. (2014). Glucocerebrosidase is shaking up the synucleinopathies. Brain 137, 1304-1322. doi: 10.1093/brain/ awu002

Smith, E. L., and Schuchman, E. H. (2008). The unexpected role of acid sphingomyelinase in cell death and the pathophysiology of common diseases. FASEB J. 22, 3419-3431. doi: 10.1096/fj.08-108043

Smith, N. J., Fuller, M., Saville, J. T., and Cox, T. M. (2018). Reduced cerebral vascularization in experimental neuronopathic Gaucher disease. J. Pathol. 244, 120-128. doi: 10.1002/path.4992

Sonnino, S., and Prinetti, A. (2013). Membrane domains and the "lipid raft" concept. Curr. Med. Chem. 20, 4-21. doi: 10.2174/0929867311320010003

Spiegel, S. (1989). Inhibition of protein kinase C-dependent cellular proliferation by interaction of endogenous ganglioside GM1 with the B subunit of cholera toxin. J. Biol. Chem. 264, 16512-16517.

Sprong, H., Kruithof, B., Leijendekker, R., Slot, J. W., van Meer, G., and van der Sluijs, P. (1998). UDP-galactose:ceramide galactosyltransferase is a class I integral membrane protein of the endoplasmic reticulum. J. Biol. Chem. 273, 25880-25888. doi: 10.1074/jbc.273.40.25880

Stanic, A. K., De Silva, A. D., Park, J. J., Sriram, V., Ichikawa, S., Hirabyashi, Y., et al. (2003). Defective presentation of the CD1d1-restricted natural Va14Ja18 NKT lymphocyte antigen caused by beta-D-glucosylceramide synthase deficiency. Proc. Natl. Acad. Sci. U.S.A. 100, 1849-1854. doi: 10.1073/pnas.0430327100

Sugiyama, E., and Setou, M. (2018). Visualization of brain gangliosides using MALDI imaging mass spectrometry. Methods Mol. Biol. 1804, 223-229. doi: 10.1007/978-1-4939-8552-4_10

Svensson, M., Frendeus, B., Butters, T., Platt, F., Dwek, R., and Svanborg, C. (2003). Glycolipid depletion in antimicrobial therapy. Mol. Microbiol. 47, 453-461. doi: 10.1046/j.1365-2958.2003.03306.x

Tagami, S., Inokuchi Ji, J., Kabayama, K., Yoshimura, H., Kitamura, F., Uemura, S., et al. (2002). Ganglioside GM3 participates in the pathological conditions of insulin resistance. J. Biol. Chem. 277, 3085-3092. doi: 10.1074/jbc.M103705200 
Taguchi, Y. V., Liu, J., Ruan, J., Pacheco, J., Zhang, X., Abbasi, J., et al. (2017). Glucosylsphingosine promotes $\alpha$-synuclein pathology in mutant GBAassociated Parkinson's disease. J. Neurosci. 37, 9617-9631. doi: 10.1523/ JNEUROSCI.1525-17.2017

Thudichum, J. (1884). A Treatise on the Chemical Constitution of the Brain. London: Bailliere, Tindall and Cox.

Tidhar, R., and Futerman, A. H. (2013). The complexity of sphingolipid biosynthesis in the endoplasmic reticulum. Biochim. Biophys. Acta 1833, 25112518. doi: 10.1016/j.bbamcr.2013.04.010

Tobias, F., Olson, M. T., and Cologna, S. M. (2018). Mass spectrometry imaging of lipids: untargeted consensus spectra reveal spatial distributions in NiemannPick disease type C1. J. Lipid Res. 59, 2446-2455. doi: 10.1194/jlr.D08609

Tsai, B., Gilbert, J. M., Stehle, T., Lencer, W., Benjamin, T. L., and Rapoport, T. A. (2003). Gangliosides are receptors for murine polyoma virus and SV40. EMBO J. 22, 4346-4355. doi: 10.1093/emboj/cdg439

Tsokos, G. C. (2011). Systemic lupus erythematosus. N. Engl. J. Med. 365, 21102121.

Van den Bergh, F. A., and Tager, J. M. (1976). Localization of neutral glycosphingolipids in human plasma. Biochim. Biophys. Acta 441, 391-402. doi: 10.1016/0005-2760(76)90236-8

van Eijk, M., Aten, J., Bijl, N., Ottenhoff, R., van Roomen, C. P., Dubbelhuis, P. F., et al. (2009). Reducing glycosphingolipid content in adipose tissue of obese mice restores insulin sensitivity, adipogenesis and reduces inflammation. PLoS One 4:e4723. doi: 10.1371/journal.pone.0004723

van Heyningen, S. (1974). Cholera toxin: interaction of subunits with ganglioside GM1. Science 183, 656-657. doi: 10.1126/science.183.4125.656

van Meel, E., Bos, E., van der Lienden, M. J. C., Overkleeft, H. S., van Kasteren, S. I., Koster, A. J., et al. (2019). Localization of active endogenous and exogenous $\beta$-glucocerebrosidase by correlative light-electron microscopy in human fibroblasts. Traffic 20, 346-356. doi: 10.1111/tra.12641

van Meer, G., Wolthoorn, J., and Degroote, S. (2003). The fate and function of glycosphingolipid glucosylceramide. Philos. Trans. R. Soc. Lond. B Biol. Sci. 358, 869-873. doi: 10.1098/rstb.2003.1266

Van Smeden, J., and Bouwstra, J. A. (2016). Stratum corneum lipids: their role for the skin barrier function in healthy subjects and atopic Dermatitis patients. Curr. Probl. Dermatol 49, 8-26. doi: 10.1159/000441540

Van Smeden, J., Dijkhoff, I. M., Helder, R. W. J., Al-Khakany, H., Boer, D. E. C., Schreuder, A., et al. (2017). In situ visualization of glucocerebrosidase in human skin tissue: zymography versus activity-based probe labeling. J. Lipid Res. 58, 2299-2309. doi: 10.1194/jlr.M079376

van Weely, S., Brandsma, M., Strijland, A., Tager, J. M., and Aerts, J. M. (1993). Demonstration of the existence of a second, non-lysosomal glucocerebrosidase that is not deficient in Gaucher disease. Biochim. Biophys. Acta 1181, 55-62. doi: 10.1016/0925-4439(93)90090-n

Vens-Cappell, S., Kouzel, I. U., Kettling, H., Soltwisch, J., Bauwens, A., Porubsky, S., et al. (2016). On-tissue phospholipase C digestion for enhanced MALDIMS imaging of neutral glycosphingolipids. Anal. Chem. 88, 5595-5599. doi: 10.1021/acs.analchem.6b01084

Vissers, J. P., Langridge, J. I., and Aerts, J. M. (2007). Analysis and quantification of diagnostic serum markers and protein signatures for Gaucher disease. Mol. Cell. Proteomics 6, 755-766. doi: 10.1074/mcp.M600303-MCP200

Wang, J., Wang, C., and Han, X. (2019). Tutorial on lipidomics. Anal. Chim. Acta 1061, 28-41. doi: 10.1016/j.aca.2019.01.043

Wang, M., Wang, C., and Han, X. (2017). Selection of internal standards for accurate quantification of complex lipid species in biological extracts by electrospray ionization mass spectrometry-What, how and why? Mass Spectrom. Rev. 36, 693-714. doi: 10.1002/mas.21492
Wennekes, T., Meijer, A. J., Groen, A. K., Boot, R. G., Groener, J. E., van Eijk, M., et al. (2010). Dual-action lipophilic iminosugar improves glycemic control in obese rodents by reduction of visceral glycosphingolipids and buffering of carbohydrate assimilation. J. Med. Chem. 53, 689-698. doi: 10.1021/ jm901281m

Wennekes, T., van den Berg, R. J., Boot, R. G., van der Marel, G. A., Overkleeft, H. S., and Aerts, J. M. (2009). Glycosphingolipids-nature, function, and pharmacological modulation. Angew. Chem. Int. Ed. Engl. 48, 8848-8869. doi: 10.1002/anie.200902620

Wertz, P. (2018). Epidermal lamellar granules. Skin Pharmacol. Physiol. 31, 262268. doi: $10.1159 / 000491757$

Williams, S. J. (2017). Sensing lipids with mincle: structure and function. Front. Immunol. 8:1662. doi: 10.3389/fimmu.2017.01662

Wisse, P., Gold, H., Mirzaian, M., Ferraz, M. J., Lutteke, G., Van Den Berg, R. J. B. H. N., et al. (2015). Synthesis of a panel of carbon-13-labelled (glyco)sphingolipids. Eur. J. Org. Chem. 12, 2661-2677. doi: 10.1002/ejoc.201500025

Witte, M. D., Kallemeijn, W. W., Aten, J., Li, K. Y., Strijland, A., DonkerKoopman, W. E., et al. (2010). Ultrasensitive in situ visualization of active glucocerebrosidase molecules. Nat. Chem. Biol. 6, 907-913. doi: 10.1038/ nchembio.466

Wu, Y., Gulbins, E., and Grassmé, H. (2018). The function of sphingomyelinases in mycobacterial infections. Biol. Chem. 399, 1125-1133. doi: 10.1515/hsz-20180179

Xia, B. T., Beckmann, N., Winer, L. K., Pugh, A. M., Pritts, T. A., Nomellini, V., et al. (2019). Amitriptyline reduces inflammation and mortality in a murine model of sepsis. Cell Physiol. Biochem. 52, 565-579. doi: 10.33594/000000040

Yamashita, T., Hashiramoto, A., Haluzik, M., Mizukami, H., Beck, S., Norton, A., et al. (2003). Enhanced insulin sensitivity in mice lacking ganglioside GM3. Proc. Natl. Acad. Sci. U.S.A. 100, 3445-3449. doi: 10.1073/pnas.063589 8100

Zelnik, I. D., Ventura, A. E., Kim, J. L., Silva, L. C., and Futerman, A. H. (2019). The role of ceramide in regulating endoplasmic reticulum function. Biochim. Biophys. Acta Mol. Cell Biol. Lipids 1865:S1388-1981(19)30118-30110. doi: 10. 1016/j.bbalip.2019.06.015

Zhang, T., de Waard, A. A., Wuhrer, M., and Spaapen, R. M. (2019). The role of glycosphingolipids in immune cell functions. Front. Immunol. 10:90. doi: 10.3389/fimmu.2019.00090

Zhao, H., Przybylska, M., Wu, I. H., Zhang, J., Maniatis, P., Pacheco, J., et al. (2009). Inhibiting glycosphingolipid synthesis ameliorates hepatic steatosis in obese mice. Hepatology 50, 85-93. doi: 10.1002/hep.22970

Zuidscherwoude, M., de Winde, C. M., Cambi, A., and van Spriel, A. B. (2014). Microdomains in the membrane landscape shape antigen-presenting cell function. J. Leukoc. Biol. 95, 251-263. doi: 10.1189/jlb.0813440

Zuverink, M., and Barbieri, J. T. (2018). Protein toxins that utilize gangliosides as host receptors. Prog. Mol. Biol. Transl. Sci. 156, 325-354. doi: 10.1016/bs.pmbts. 2017.11.010

Conflict of Interest: The authors declare that the research was conducted in the absence of any commercial or financial relationships that could be construed as a potential conflict of interest.

Copyright (C) 2019 Aerts, Artola, van Eijk, Ferraz and Boot. This is an open-access article distributed under the terms of the Creative Commons Attribution License (CC BY). The use, distribution or reproduction in other forums is permitted, provided the original author(s) and the copyright owner(s) are credited and that the original publication in this journal is cited, in accordance with accepted academic practice. No use, distribution or reproduction is permitted which does not comply with these terms. 